\title{
A Standardized Set of 260 Pictures: Norms for Name Agreement, Image Agreement, Familiarity, and Visual Complexity
}

\author{
Joan Gay Snodgrass and Mary Vanderwart \\ New York University
}

\begin{abstract}
In this article we present a standardized set of 260 pictures for use in experiments investigating differences and similarities in the processing of pictures and words. The pictures are black-and-white line drawings executed according to a set of rules that provide consistency of pictorial representation. The pictures have been standardized on four variables of central relevance to memory and cognitive processing: name agreement, image agreement, familiarity, and visual complexity. The intercorrelations among the four measures were low, suggesting that they are indices of different attributes of the pictures. The concepts were selected to provide exemplars from several widely studied semantic categories. Sources of naming variance, and mean familiarity and complexity of the exemplars, differed significantly across the set of categories investigated. The potential significance of each of the normative variables to a number of semantic and episodic memory tasks is discussed.
\end{abstract}

Investigators studying aspects of verbal processes have long had access to extensive normative data on various objective and subjective dimensions of their verbal materials. Brown (1976) recently compiled a catalog of scaled verbal materials that included 172 studies providing such information. For the set of verbal materials most comparable to the present set of pictures-English nouns - such dimensions include objective measures of frequency of occurrence and subjective measures of familiarity, age of acquisition, concreteness, imagery, meaningfulness, and emotionality.

In contrast, normative data on characteristics of pictorial representations of concrete

This research was supported by Research Grant MH-20723 from the National Institute of Mental Health, U.S. Public Health Service, and by a Biomedical Research Support Grant to New York University from the National Institutes of Health, U.S. Public Health Service.

The authors would like to thank Maryann McManus, Anthony Vallone, Spencer Fischer, and Carolyn Gleeman for help at all stages of the design, data collection, and analysis.

Requests for reprints should be sent to Joan Gay Snodgrass, Department of Psychology, New York University, 6 Washington Place, New York, New York 10003. nouns, whose use in experiments in both semantic and episodic memory tasks has proliferated in recent years, have been lacking. Because there are so many different ways to draw even the simplest object, each investigator has been forced to develop his or her own set of pictures that must necessarily be highly idiosyncratic. We cannot assume that the results of studies employing such different representations of the same concepts are comparable. In addition, the degree to which each picture possesses characteristics that affect the process under investigation is unknown.

In recognition of this long overdue need for a standardized set of picture stimuli, we present here a new set of 260 pictures that are standardized on several variables of potential importance to cognitive processing tasks. The pictures are presented in Appendix $A$ and the accompanying norms in Appendix B. In addition, slides of the pictures and their names are available from a commercial publisher. ${ }^{1}$

\footnotetext{
1 Slides of the pictures or of their names may be ordered from Life Science Associates, 1 Fenimore Road, Bayport, NY 11705.
} 
In the next sections, we first briefly review evidence for processing differences between pictures and words in semantic and episodic memory tasks, and then describe the assumptions and procedures we used to construct the picture set.

\section{Processing Differences Between Pictures and Words}

Processing of pictures and words has been compared in many different tasks and for many different reasons. We can classify these tasks into two broad categories-those tapping semantic memory, a general knowledge store shared by most subjects, and those tapping episodic memory, an event knowledge store about the occurrence of events in time and space that is idiosyncratic to individual subjects (Tulving, 1972). Semantic memory tasks include naming pictures and words, generating images to words, categorizing pictures or their names, and making symbolic comparison judgments about whether $X$ has more of some property than Y. Episodic memory tasks include the standard verbal learning and memory paradigms, such as free and serial recall, paired-associate recall, yes/no or forcedchoice recognition, serial and spatial reconstruction and recognition, and so forth. The questions that emerge from these two classes of tasks are, first, how pictures and words differ in their access to semantic memory, and second, how they differ in their registration in episodic memory. In this necessarily brief review of empirical differences between pictures and words we shall consider two semantic memory tasks-naming and categorization-and two episodic memory tasks-recognition and free recall.

\section{Semantic Memory Tasks}

Naming. Naming latencies, as measured by voice key activation, are faster for words than for pictures (Cattell, 1886; Fraisse, 1960; Potter \& Faulconer, 1975). Furthermore, certain characteristics of the picture's name, such as frequency in print, have much larger effects on naming latencies of pictures than on reading latencies of the picture's name (Oldfield \& Wingfield, 1965). However, there is disagreement about which of several variables correlated with frequency in print is primarily responsible for the differences in picture-naming latencies. Carroll and White (1973b) found that age of acquisition of a concept's name was more predictive of naming latencies than frequency and, in fact, that frequency was insignificant in predicting naming latencies when the age-of-acquisition variable was included in the multiple regression. Lachman (1973) measured the degree to which subjects agreed on the name of the picture with the information statistic $H$ and found that $H$ was more predictive of naming latencies of pictures than either age of acquisition or frequency in print, although the latter two variables generally predicted significant amounts of variance in the naming latencies. However, individual subjects varied in the degree to which each of the three variables predicted latencies. To understand the picture-naming process, then, it is clear that one must know at least the following characteristics of each picturethe frequency of its name in print, the age of acquisition of its name, and its degree of name agreement.

Categorization. Tasks in which the meaning of pictures or their names must be accessed have been used to study the question of whether pictures and their names access a common semantic representation. In a categorization task, there is ample evidence that pictures are categorized faster than their names. For example, in a yes/no task in which the category is given ahead of time, pictures are categorized either faster than words (Potter \& Faulconer, 1975) or with the same speed (Smith \& Magee, in press). In a samedifferent task, when two instances of pictures or words in a same or different category are presented simultaneously, pictures result in faster match or mismatch decisions than words (Pellegrino, Rosinski, Chiesi, $\&$ Siegel, 1977). Furthermore, comparisons between picture and word forms of exem- 
plars of categories were made with latencies intermediate to the picture-picture and word-word comparisons. These data may be interpreted as indicating that pictures and words access a common semantic representation that is neither verbal nor imaginal in nature. That is, if determining membership were dependent on accessing the exemplar's name, then pictures would take longer to categorize than names because naming pictures takes longer than naming words.

However, these data could as easily be accounted for by assuming that categorization is based on access to imaginal codes. This would account for faster categorization of pictures than their names and for the data of Pellegrino et al. (1977) on mixed form comparisons. This hypothesis is also consistent with Paivio's (1978) recent argument that such attributes as size, value, and intelligence are stored at the image level and may be in the form of remembered motor/visceral reactions.

\section{Episodic Memory Tasks}

In episodic memory tasks, an impressive array of evidence suggests that pictorial material is remembered better than verbal material, when memory is tested either by recognition (Nickerson, 1965; Shepard, 1967; Snodgrass \& McClure, 1975 ; Standing, Conezio, \& Haber, 1970) or by recall (Bousfield, Esterson, \& Whitmarsh, 1957; Paivio, Rogers, \& Smythe, 1968). There are at least three hypotheses that have been proposed for the superiority of pictures over words: dual coding, superior sensory codes, and uniqueness of entry in semantic memory.

According to Paivio's dual coding model, pictures are better remembered than words in most tasks for one or both of two reasons : First, pictures are more likely to be dually coded than words (i.e., registered in both the image and verbal stores); and second, the image code, which is more likely to be stored to a picture than to a word, is the more effective code for item memory (Paivio, 1971; Paivio \& Csapo, 1973). For example, when subjects are instructed to form visual images of words and to name pictures (which presumably provides dual codes for both types of materials), recall performance is equal for pictures and words (Paivio \& Csapo, 1973), although recognition performance continues to be superior for pictures over words under such dual-coding instructions (Snodgrass \& McClure, 1975). Further evidence that pictures are more likely to be dually encoded than words, in the absence of instructions, comes from the finding that subjects have difficulty deciding between a studied picture and its name, in a forced-choice recognition test (Snodgrass, Wasser, Finkelstein, \& Goldberg, 1974), and from the lack of improvement in item recognition memory for pictures studied under verbal encoding instructions over those studied under imagery instructions (Snodgrass \& McClure, 1975). In contrast to this evidence, Intraub (1979) has found that picture-naming latency and presentation time do not interact in a recognition or recall memory task, thereby providing no evidence that implicit naming improved picture memory at slow presentation rates.

The superior sensory code hypothesis, proposed by Nelson and his colleagues, attributes the pictorial superiority effect to the more elaborate sensory codes of pictures as compared to words (Nelson, Reed, \& McEvoy, 1977; Nelson, Reed, \& Walling, 1976). They found that increasing the visual similarity of a set of pictures in a paired-associate recall task, while keeping conceptual similarity constant, had the effect of destroying, and even reversing, the superiority of pictures over words.

The third hypothesis, that pictures are remembered better than words because of their uniqueness in semantic memory, has been proposed by Durso and Johnson (1979) and Snodgrass (Note 1). The argument here is that words, even concrete names, are more polysemous than pictures, and hence their semantic representation is less likely to be contacted on a recognition test or retrieved during recall than the word's corresponding picture. This argument is similar to that made by critics of the encoding specificity hypothesis of Tulving 
and Thomson (1971), who argue that changing word context from study to test effectively changes which entry is accessed in semantic memory (Anderson \& Bower, 1974; Martin, 1975; Reder, Anderson, \& Bjork, 1974). A related hypothesis has been proposed by Potter, Valian, and Faulconer (1977) to account for the finding that although relatedness of a probe to a sentence could be decided as quickly for picture as for word probes, suggesting an abstract format for sentence meaning, probe pictures were recalled better than probe words. They attribute the superiority of pictures to greater specificity of meaning of the picture.

Of course, the three hypotheses are not mutually exclusive: It could be the case that all three attributes of pictures-their greater probability of dual coding, their more elaborate sensory codes, and their uniqueness of meaning-jointly account for the superiority of pictures over words in episodic memory.

Regardless of the theoretical arguments advanced for the differential efficiency of pictures and words in contacting information in semantic memory or of being registered in episodic memory, it is clear that there are important parameters characterizing the interlingua between pictures and their names that need to be established. It is the aim of the present study to investigate and measure some of these parameters.

\section{Development of the Present Study}

The present study evolved in two steps. First, we selected the concepts to be drawn and established a set of guidelines for the manner in which they were to be drawn. Second, we decided which of several possible types of information about the pictures we would collect.

The 260 concepts were selected on the basis of three criteria: first, that they be unambiguously picturable; second, that they include exemplars from the widely used category norms of Battig and Montague (1969); and third, that they represent concepts at the basic level of categorization (Rosch, Mervis, Gray, Johnson, \& BoyesBraem, 1976).
The first criterion, that concepts be unambiguously picturable, is a matter of degree. What we mean by this, operationally, is the degree to which subjects will show consensus about the name to give the object. There are several sources of naming ambiguity for pictures. These sources stem from the concept itself, the picture itself, the possible name or names a picture can have, and the subjects' knowledge of concepts and their names.

Some concepts are, by their very nature, not unambiguously picturable. These include concepts of relationship (father, sister), mass nouns (money, water, grass), and abstract concepts (liberty, time, honesty). Some pictures, by the way they are drawn, are not easily recognizable for what they are. That is, they are drawn in an atypical way or with too little detail to make their identity clear. As we shall discuss, we have attempted to avoid this problem. Some concepts simply can be called by more than one name, even though the names appear to mean the same thing to subjects. Object names that appear to be nearly synonymous include phonograph/ record player, trumpet/horn, and purse/ pocketbook. We have included such concepts in the set and have indicated the cases in which synonymous terms account for name ambiguity. Finally, some concepts, because they are unfamiliar to subjects, also are not known to them by name, even though they are recognizable as exemplars of a particular category. For example, artichoke and chisel may not be known by name, but subjects are aware that they belong to the categories of vegetables and tools, respectively. These sources of ambiguity are also identified in the norms.

The second criterion, that the set of pictures include exemplars from wellstudied categories, is important because of their potential use in category-judgment tasks. We have used the Battig and Montague (1969) category norms as a guide. Of the 56 categories studied by Battig and Montague, 15 contain many

(text continued on p. 180) 
Table 1

Concepts and their Ranks, from the Battig and Montague Category Norms

\begin{tabular}{|c|c|c|c|}
\hline Concept & Rank & Concept & Rank \\
\hline \multicolumn{2}{|c|}{ Four-footed animal (30) } & \multicolumn{2}{|c|}{ Article of furniture (continued) } \\
\hline Alligator & 63 & Clock & 64 \\
\hline Bear & 9 & Couch & 7 \\
\hline Camel & 28 & Desk & 5 \\
\hline Cat & 2 & Dresser & 8 \\
\hline Cow & 4 & Lamp & 6 \\
\hline Deer & 12 & *Piano & 17 \\
\hline Dog & 1 & Record player & 55 \\
\hline Donkey & 19.5 & *Refrigerator & 30 \\
\hline Elephant & 7 & Rocking chair & 49.5 \\
\hline Fox & 23 & Stool & 10 \\
\hline Frog & 75 & *Stove & 35 \\
\hline Giraffe & 14 & Table & 2 \\
\hline Goat & 15 & Television & 9 \\
\hline Gorilla & 86 & Vase & 64 \\
\hline Horse & 3 & \multirow{2}{*}{\multicolumn{2}{|c|}{ Part of the human body (12) }} \\
\hline $\begin{array}{l}\text { Kangaroo } \\
\text { Leopard }\end{array}$ & $\begin{array}{l}75 \\
21.5\end{array}$ & & \\
\hline Lion & 5 & Arm & 2 \\
\hline Monkey & 32.5 & Ear & 8 \\
\hline Mouse & 10 & Eye & 4 \\
\hline Pig & 8 & Finger & 7 \\
\hline Rabbit & 19.5 & Foot & 5 \\
\hline Raccoon & 32.5 & Hair & 13 \\
\hline Rhinoceros & 27 & Hand & 9 \\
\hline Sheep & 13 & †Heart & 15 \\
\hline Skunk & 36 & Leg & 1 \\
\hline Squirrel & 17 & Lips & 33.5 \\
\hline Tiger & 6 & Nose & 6 \\
\hline Turtle & 40.5 & Thumb & 45 \\
\hline Zebra & 16 & Toe & 10 \\
\hline \multicolumn{2}{|c|}{ Kitchen utensil (14) } & \multicolumn{2}{|c|}{ Fruit (11) } \\
\hline Bowl & 9 & Apple & 1 \\
\hline Broom & 98 & Banana & 4 \\
\hline${ }^{*}$ Clock & 76 & Cherry & 7 \\
\hline Cup & 11 & Grapes & 6 \\
\hline Fork & 3 & Lemon & 10 \\
\hline Frying pan & 15 & Orange & 2 \\
\hline Glass & 21 & Peach & 5 \\
\hline Kettle & 44.5 & Pear & 3 \\
\hline Knife & 1 & Pineapple & 13 \\
\hline Pot & 5 & Strawberry & 16 \\
\hline Refrigerator & 18.5 & *Tomato & 15 \\
\hline Rolling pin & 28.5 & Watermelon & 17 \\
\hline $\begin{array}{l}\text { *Scissors } \\
\text { Spoon }\end{array}$ & $\begin{array}{r}76 \\
2\end{array}$ & \multirow{2}{*}{\multicolumn{2}{|c|}{ Weapon (7) }} \\
\hline Stove & 8 & & \\
\hline *Table & 49.5 & \multirow{6}{*}{$\begin{array}{l}\text { *Airplane } \\
\text { *Arm } \\
\text { Axe } \\
\text { *Bat (baseball) } \\
\text { *Book } \\
\text { Bottle } \\
\text { Cannon } \\
\text { *Car }\end{array}$} & 39.5 \\
\hline Toaster & 22 & & 109 \\
\hline \multicolumn{2}{|c|}{ Article of furniture (14) } & & $\begin{array}{r}10 \\
53 \\
109\end{array}$ \\
\hline Ashtray & 49.5 & & 61.5 \\
\hline Bed & 3 & & 10 \\
\hline Chair & 1 & & 30.5 \\
\hline
\end{tabular}


Table 1 (continued)

\begin{tabular}{|c|c|c|c|}
\hline Concept & Rank & Concept & Rank \\
\hline \multicolumn{2}{|c|}{ Weapon (continued) } & \multicolumn{2}{|c|}{ Part of a building (continued) } \\
\hline \multirow{11}{*}{$\begin{array}{l}\text { Chain } \\
\text { "Chair } \\
\text { *Foot } \\
\text { *Fork } \\
\text { Gun } \\
\text { *Hammer } \\
\text { *Hand } \\
\text { †'Knife } \\
\text { *Nail } \\
\text { *Scissors } \\
\text { *Screwdriver } \\
\text { *Shoe } \\
\text { *Wrench }\end{array}$} & \multirow{11}{*}{$\begin{array}{l}22 \\
87.5 \\
44.5 \\
87.5 \\
2 \\
24 \\
26 \\
1 \\
109 \\
44.5 \\
87.5 \\
87.5 \\
69\end{array}$} & \multirow{5}{*}{$\begin{array}{l}\text { Door } \\
\text { Doorknob } \\
\text { †Lock } \\
\text { *Nail } \\
\text { Window }\end{array}$} & \multirow{5}{*}{$\begin{array}{r}2 \\
95 \\
123 \\
52 \\
1\end{array}$} \\
\hline & & & \\
\hline & & & \\
\hline & & & \\
\hline & & & \\
\hline & & \multirow{2}{*}{\multicolumn{2}{|c|}{ Musical instrument (9) }} \\
\hline & & & \\
\hline & & \multirow{8}{*}{$\begin{array}{l}\text { Accordion } \\
\dagger^{*} \text { Bell } \\
\text { Drum } \\
\text { Flute } \\
\text { French horn } \\
\text { Guitar } \\
\text { Harp } \\
\text { Piano } \\
\text { Trumpet } \\
\text { Violin }\end{array}$} & 24 \\
\hline & & & 34 \\
\hline & & & $\begin{array}{l}2 \\
6\end{array}$ \\
\hline & & & 17 \\
\hline \multicolumn{2}{|c|}{ Carpenter's tool (12) } & & 12 \\
\hline \multirow{15}{*}{$\begin{array}{l}\text { *Axe } \\
\dagger^{*} \text { Box } \\
\text { Chisel } \\
\text { Hammer } \\
\dagger^{*} \text { Knife } \\
\text { Ladder } \\
\text { Nail } \\
\text { Nut } \\
\text { Pencil } \\
\text { Pliers } \\
\text { Ruler } \\
\text { Saw } \\
\text { *Scissors } \\
\text { Screw } \\
\text { Screwdriver } \\
\text { Wrench }\end{array}$} & & & 1 \\
\hline & $\begin{array}{l}28 \\
73\end{array}$ & & 3 \\
\hline & 7 & & 4 \\
\hline & 1 & \multirow{2}{*}{\multicolumn{2}{|c|}{ Bird (8) }} \\
\hline & 30 & & \\
\hline & 31.5 & \multirow{8}{*}{$\begin{array}{l}\text { Chicken } \\
\text { Duck } \\
\text { Eagle } \\
\text { Ostrich } \\
\text { Owl } \\
\text { Peacock } \\
\text { Penguin } \\
\text { Rooster }\end{array}$} & 21 \\
\hline & 3 & & 23.5 \\
\hline & 34 & & 5 \\
\hline & 14.5 & & 33.5 \\
\hline & 10 & & 23.5 \\
\hline & 8 & & 37 \\
\hline & 2 & & 40.5 \\
\hline & 51.5 & & 53.5 \\
\hline & $\begin{array}{r}12 \\
4\end{array}$ & \multicolumn{2}{|c|}{ Type of vehicle (10) } \\
\hline & 9 & \multirow{12}{*}{$\begin{array}{l}\text { Airplane } \\
\text { †*Balloon } \\
\text { Bicycle } \\
\text { Bus } \\
\text { Car } \\
\text { Helicopter } \\
\text { *Horse } \\
\text { Motorcycle } \\
\text { Roller skate } \\
\text { Sled } \\
\text { Train } \\
\text { Truck } \\
\dagger^{*} \text { Wagon }\end{array}$} & \multirow{3}{*}{$\begin{array}{c}3 \\
53.5 \\
6\end{array}$} \\
\hline \multicolumn{2}{|c|}{ Article of clothing (19) } & & \\
\hline \multirow{17}{*}{$\begin{array}{l}\text { Belt } \\
\text { Blouse } \\
\text { Boot } \\
\text { Cap } \\
\text { Coat } \\
\text { Dress } \\
\text { Glove } \\
\text { Hat } \\
\text { Jacket } \\
\text { Pants } \\
\text { Ring } \\
\text { Shirt } \\
\text { Shoe } \\
\text { Skirt } \\
\text { Sock } \\
\text { Sweater } \\
\text { Tie } \\
\text { Vest } \\
\text { Watch }\end{array}$} & 16 & & \\
\hline & 5.5 & & 2 \\
\hline & 40 & & $\begin{array}{r}1 \\
26\end{array}$ \\
\hline & 38 & & 32 \\
\hline & 7 & & 7 \\
\hline & $\begin{array}{r}8 \\
15\end{array}$ & & 37 \\
\hline & 9 & & 34 \\
\hline & 13.5 & & 4 \\
\hline & 3 & & 5 \\
\hline & 40 & & 10 \\
\hline & 1 & \multirow{2}{*}{\multicolumn{2}{|c|}{ Toy (18) }} \\
\hline & 4 & & \\
\hline & $\begin{array}{l}5.5 \\
2\end{array}$ & \multirow{7}{*}{$\begin{array}{l}\text { *Airplane } \\
\text { Baby carriage } \\
\text { Ball } \\
\text { Balloon } \\
\text { Bat (baseball) } \\
\dagger * \text { Bear } \\
\text { Bell } \\
\text { *Bicycle } \\
\text { Book } \\
\text { *Boot }\end{array}$} & \multirow{7}{*}{$\begin{array}{l}13.5 \\
54.5 \\
2 \\
26 \\
9 \\
93 \\
76.5 \\
22 \\
35 \\
123\end{array}$} \\
\hline & 10 & & \\
\hline & 11 & & \\
\hline & 26 & & \\
\hline & 46.5 & & \\
\hline \multicolumn{2}{|c|}{ Part of a building (3) } & & \\
\hline $\begin{array}{l}\text { *Chair } \\
{ }^{*} \text { Desk }\end{array}$ & $\begin{array}{l}41.5 \\
52\end{array}$ & & \\
\hline
\end{tabular}


Table 1 (continued)

\begin{tabular}{|c|c|c|c|}
\hline Concept & Rank & Concept & Rank \\
\hline \multicolumn{2}{|c|}{ Toy (continued) } & \multicolumn{2}{|c|}{ Toy (continued) } \\
\hline Box & 93 & Wagon & 15 \\
\hline *Cannon & 123 & Whistle & 63.5 \\
\hline${ }^{*} \mathrm{Car}$ & 3 & \multirow{2}{*}{\multicolumn{2}{|c|}{ Vegetable (13) }} \\
\hline *Cat & 93 & & \\
\hline${ }^{*}$ Clock & 123 & & \\
\hline Clown & 76.5 & $\begin{array}{l}\text { Artichoke } \\
\text { Asparagus }\end{array}$ & $\begin{array}{r}32 \\
9\end{array}$ \\
\hline *Dog & 51 & $\begin{array}{l}\text { Asparagus } \\
\text { Carrot }\end{array}$ & 1 \\
\hline Doll & 1 & Celery & 11 \\
\hline *Drum & 35 & Corn & 3 \\
\hline$f^{*}$ Duck & 123 & Lettuce & 7 \\
\hline Football & 35 & Mushroom & 46 \\
\hline$\dagger^{*}$ Glove & 45.5 & Onion & 18 \\
\hline${ }^{*} \mathrm{Gun}$ & 4.5 & Peanut & 36 \\
\hline *Hammer & 51 & *Pear & 46 \\
\hline${ }^{*}$ Hat & 93 & Pepper & 26 \\
\hline${ }^{*}$ Horse & 30.5 & Potato & 5 \\
\hline †House & 57 & Pumpkin & 46 \\
\hline Kite & 63.5 & Tomato & 6 \\
\hline${ }^{*}$ Knife & 63.5 & ${ }^{*}$ Watermelon & 46 \\
\hline "Roller skate & 51 & \multirow{2}{*}{\multicolumn{2}{|c|}{ Insect (8) }} \\
\hline Sailboat & 123 & & \\
\hline *Sled & 63.5 & Ant & 2 \\
\hline *Stove & 76.5 & Bee & 3.5 \\
\hline Swing & 45.5 & Beetle & 6 \\
\hline Telephone & 93 & Butterfly & 14 \\
\hline Top & $\begin{array}{l}90 \\
10\end{array}$ & Caterpillar & 21 \\
\hline & 10 & Fly & 1 \\
\hline Train & 6 & Grasshopper & 9 \\
\hline${ }^{*}$ Truck & 4.5 & Spider & 5 \\
\hline
\end{tabular}

Note. A dagger indicates that the picture does not represent the meaning intended by the name, and an asterisk indicates that this exemplar appears with higher frequency in another category in the table (except when it is daggered). Frequencies in parentheses beside each category indicate the number of unasterisked or undaggered concepts.

picturable exemplars, such as four-footed animals, kitchen utensils, and human body parts. Table 1 lists the 189 concepts included in the set of pictures that are members of one or more of these 15 Battig and Montague categories. Only categories having more than five exemplars in the picture set are included, and only names given by more than one respondent in the Battig and Montague study are shown in the table.

The rank by frequency of the concept in each category is shown next to its name. Concepts with high ranks, such as dog for four-footed animal and chair for article of furniture, were given by many subjects, whereas those with low ranks, such as gorilla for four-footed animal and vase for article of furniture, were given by few subjects. Thus it is possible to vary the degree to which category exemplars are prototypical of the category.

A number of the concepts appear in more than one category. For example, airplane appears as a weapon, a type of vehicle, and a toy. Of course, multiplecategory concepts differ in their ranking across the categories; those concepts that are of lower typicality (e.g., airplane as a weapon and toy) are identified with asterisks. Furthermore, the particular sense of a name is not always instantiated in its 
picture. For example, the knife, which is listed as the most typical exemplar of the category weapon, is surely not the same knife that is listed as the most typical exemplar of the category kitchen utensil in its imaged or pictured form. The picture of a knife included in the present set corresponds to the second sense rather than the first. Similarly, the pictured heart does not represent the sense of the heart given as an exemplar of the category part of the human body. Pictures that in our judgment do not represent the meaning of the category exemplar are indicated by a dagger in Table 1. Thus, the rank of the Battig and Montague names will correspond to the rank of their corresponding pictures only to the extent that the picture represents the meaning intended in the name given by respondents.

The 71 remaining pictures, not exemplars of any of the Battig and Montague categories listed in Table 1, are not assignable to any well-defined category (e.g., anchor, barrel, flag), or are members of categories from the Battig and Montague norms having too few exemplars in this picture set to be useful (e.g., house, church, and barn), or are members of small categories not studied by Battig and Montague (e.g., cigar, cigarette, and pipe; needle, thread, and thimble). These concepts were included in the set either because they are easily drawn or because they have been used by other investigators.

The third criterion, that the concepts be represented at their basic level, seems to have been implicitly followed by most investigators using pictures as stimuli. For example, pictures of the categories animal, tool, and vegetable are not used (indeed, it is not clear whether any pictorial representation could elicit these names). But, pictures of the categories bird, tree, flower, and fish, some of which Rosch et al. (1976) have shown are basic categories, have been used. Indeed, such atypical exemplars of the category bird as chicken, duck, and ostrich also appear to be basic level categories. We suggest, in fact, that another criterion for identifying whether a concept is at a basic level is whether its picture produces consensus in naming.

Once the concepts were selected, some guidelines had to be established for how they should be drawn. ${ }^{2}$ The criteria we used were that the drawing be correct (i.e., realistic) in its details, that the drawing be the most typical representation of a concept, that the drawing be an unambiguous representation of the concept, and that the drawing include the amount of detail needed to be consistent with the complexity of the real-life object. Although these criteria are admittedly subjective, a panel of four judges (consisting of the authors and two students) reached a high degree of consensus about when a drawing did, or did not, fulfill the criteria.

Another decision concerned the orientation of each figure. We adopted the following rules: (a) Animals are shown in sideways view, with approximately equal numbers facing left and right; (b) objects whose up-down orientation may vary (e.g., fork, chisel) are drawn with the functional end down; (c) long, thin objects are oriented at a $45^{\circ}$ angle, with approximately equal numbers in the two possible orientations.

The objects were drawn so as to be of approximately equal subjective size based on judgments of the two authors. To accomplish this, it was necessary to draw objectively smaller objects as slightly smaller in their pictured form than objectively larger objects. Because these subjective size decisions are very difficult to make, the size adjustments were made within categories. Thus, the drawing of mouse is smaller than that of lion, and the drawing of strawberry, smaller than that of apple.

We collected four measures on the set of 260 pictured concepts, based on the four

2 The pictures were drawn by the graphic design firm A Good Thing, Inc, 230 Park Avenue, New York, NY 10017. 
cognitive processes of naming, imaging, familiarity judgments, and complexity judgments. The four measures seemed to us to represent distinctly different aspects of pictured stimuli. First, we had subjects name the pictures to determine the picture's most common name and the degree to which subjects agreed on the name. This information is of obvious importance in naming latency studies, picture-name matching studies, recall memory studies, and recognition studies in which verbal encoding is manipulated. This set of data establishes some important parameters of the interlingua between pictures and their names.

Second, we had subjects rate the degree of agreement between their mental image of a concept and its name by presenting subjects with the most common name of each picture, asking them to image its pictorial form, and then presenting them with the picture and asking them to rate the degree to which the picture resembled their image. This set of data establishes some parameters of the interlingua between names and their images.

Because familiarity has been shown to have such important effects on various memory and cognitive processing tasks, we had subjects rate the familiarity of each pictured object. Use of the picture rather than its name in this rating is important because many concrete nouns have more than one picturable sense (e.g., nut, top, and pipe). Word frequency counts are particularly useless for this purpose because they do not distinguish between parts of speech or metaphoric versus concrete usages. For example, well and saw both have very high KučeraFrancis frequencies, primarily because of nonnoun usages, and both house and door have high frequencies, presumably because of metaphoric rather than concrete usages.

Finally, because visual complexity may affect such variables as naming latencies, tachistoscopic recognition thresholds, and perhaps memorability, we had subjects rate the visual complexity of each picture.

\section{Method}

Subjects

A total of 219 subjects participated. Forty-two subjects were run in the name agreement task, and different groups of 40 subjects served in the other three major tasks. An additional two groups of 40 and 17 subjects served in two tasks that were supplementary to the main image agreement task, picture-name agreement and image variability. All were volunteers from introductory psychology courses who participated to fulfill a course requirement, except the 17 who participated in the image variability task who were students in an experimental psychology laboratory course. All were native English speakers, and approximately equal numbers of males and females served in each of the tasks. Subjects were run in small groups of from 5 to 15 in a classroom.

\section{Stimulus Materials}

The pictures (presented in Appendix A) were black outline drawings on a white background. The drawings were photographed and made into transparent slides. Each picture occupied approximately the same subjective amount of space on the slide (as described previously).

\section{General Procedure}

The pictures were projected sequentially on a large white screen at the front of a slightly darkened room using a Kodak Carousel slide projector. Four different random sequences of the 260 slides were used by constructing two different random permutations and running each in the forward and backward order. Approximately equal numbers of subjects in each of the tasks saw each of the four sequences.

At the start of each task, subjects were read a statement that described the importance of normative data for pictures and encouraged them to respond carefully and consistently. Each slide was presented for a period of from 3 to $5 \mathrm{sec}$. Subjects recorded their responses on individual data sheets. They were instructed to respond to every slide, leaving no blanks. Halfway through the slides, the subjects were given a 5 -min rest period.

\section{Name Agreement}

Subjects were instructed to identify each picture as briefly and unambiguously as possible by writing only one name, the first name that came to mind. They were told that a name could consist of more than one word. Specific instructions, designed to elucidate the sources of naming failures, were also given. Subjects were instructed to respond DKO (don't know object) if the picture was of an object 
unknown to them. If the object was known but the name was unknown, they were to respond DKN (don't know name). And, finally, if they knew the name but it was momentarily irretrievable, they were to respond TOT (tip-of-the-tongue).

\section{Familiarity}

Subjects were asked to judge the familiarity of each picture "according to how usual or unusual the object is in your realm of experience." Familiarity was defined as "the degree to which you come in contact with or think about the concept." They were told to rate the concept itself, rather than the way it was drawn. If they did not know what the object was, they were to respond with the letters DKO.

A 5-point rating scale was used in which 1 indicated very unfamiliar and 5 indicated very familiar. In this and all rating tasks, subjects were told to assign only one whole-number value to each picture and were encouraged to employ the full range of scale values throughout the set of pictures. To give subjects an idea of the range of familiarity in the set, so as to provide anchors for the scale, the first 30 pictures in the sequence were presented to them prior to their ratings.

\section{Visual Complexity}

Subjects were instructed to rate the complexity of each picture on a 5-point scale in which 1 indicated very simple and 5 indicated very complex. Complexity was defined as the amount of detail or intricacy of line in the picture. They were told to rate the complexity of the drawing itself rather than the complexity of the real-life object it represented. As in the familiarity ratings, subjects were shown the first 30 slides in the sequence to permit them to anchor their scales.

\section{Image Agreement}

Subjects were asked to judge how closely each picture resembled their mental image of the object. At the start of the session, subjects were informed of the general nature of the pictures, that is, that they were relatively simple black-and-white outline drawings. Prior to presenting each picture, the experimenter called out the picture's most common name (as determined from data of the name agreement task), waited approximately $3 \mathrm{sec}$, and then projected the picture on the screen. During the 3-sec period, subjects looked at the darkened screen (or closed their eyes) and formed a mental image of the object named. Following the appearance of the picture on the screen, subjects rated the degree of agreement between their image and the picture using the 5-point scale. A rating of 1 indicated low agreement, that the picture provided a poor match to their image, and a rating of 5 indicated high agreement.

Subjects were instructed to write the letters NI (no image) if they could not form an image of an object for any reason. The NI response did not distinguish between two possible sources of image failure: not knowing the object to which the name referred or knowing the object but being unable to image it. If subjects imaged a different object from the one pictured (e.g., imaging a lump of metal to the name "iron," instead of a household appliance), they were to respond DO (different object).

\section{Supplementary Image Tasks}

Picture-name agreement. In this variation of the image agreement task, the experimenter called out the name of the concept concurrently with presenting its picture. Subjects were asked to rate how closely the picture matched the way they expected the object to look. Thus, in this variation subjects were not explicitly instructed to form a mental image and hence were evaluating the match between a picture and its name. The same 5-point scale was used in this task as in image agreement.

Image variability. In this variation of the image agreement task, subjects were given only the names of the concepts and asked to evaluate the potential variability in images to a particular name by rating how many different images each name could evoke. The ratings were made on a 5 -point scale in which 1 indicated that the name evoked few images and 5 indicated that the name evoked many different, and different appearing, images.

\section{Results and Discussion ${ }^{3}$}

The pictures are presented in Appendix A in alphabetical order according to the most frequent names assigned to them by the subjects. Each picture is also numbered for convenient reference to the table of norms presented in Appendix B. Appendix $C$ presents more detailed information on the nature of the difficulties that subjects encountered when naming, imaging, or rating the familiarity of the concepts.

Appendix B presents the following information for each picture: the identifying number and most frequent name; two measures of name agreement, the information statistic $H$ and the percentage of subjects giving the most common name; and the means and standard deviations for ratings of image agreement, familiarity, and visual complexity. Name and image failures were not included when computing the ratings. The Kučera-Francis (1967)

${ }^{3}$ All effects reported as significant are at the .05 level or better. 
frequency counts are also included in Appendix B for the 240 concepts with single-word names. A frequency of zero indicates that the single-word name did not occur in the Kučera-Francis corpus. Because the Kučera-Francis norms do not provide counts for names of more than one word, these unavailable frequencies are indicated by a dash. Counts for alternate spellings of a name were combined only when both spellings occurred in our subjects' naming responses (e.g., ax and axe were combined, but cigarette and cigaret were not). Either the singular or plural KučeraFrancis count was used, the one corresponding to the sense of the picture (e.g., glass for water glass and glasses for eyeglasses).

The Carroll-White (1973a) age-of-acquisition norms are given in Appendix B for the 89 names for which they were available. The age-of-acquisition norms were obtained by having adult subjects estimate the age at which they first learned the words and then converting these average estimates to a 9-point scale in which 1 represents an age of 2 years and 9 represents an age of 13 years and above.

The information statistic $H$ was computed for each picture by the formula

$$
H=\sum_{i=1}^{k} p_{i} \log _{2}\left(1 / p_{i}\right)
$$

where $k$ refers to the number of different names given each picture and $p_{i}$ is the proportion of subjects giving each name. The three categories of naming failuresDKOs (don't know object), DKNs (don't know name), and TOTs (tip-of-the-tongue) -were eliminated when computing $H$ values, but not when computing the percentage agreement scores. Thus, a picture with $H$ value of .0 can have a percentage agreement score that is less than $100 \%$ because the picture produced naming failures in some subjects.

Because so many of the concepts showed perfect name agreement (i.e., an $H$ value of .0 ), we used a strict criterion for counting different instances of names. In many cases, the name given by a subject was similar to but not identical to an established name category. These cases included misspellings, abbreviations, elaborations, and multiple names. Misspellings were included with the correctly spelled name when computing $H$, commonly accepted abbreviations such as TV for television were counted as separate names, uncommon abbreviations such as b. carriage for baby carriage were included with the unabbreviated form, elaborations such as bell pepper for pepper were counted separately, and when a subject wrote down two distinct names for a picture, only the first was counted.

A picture that elicited the same name from every subject in the sample who was able to name it has an $I I$ value of .0 and indicates perfect name agreement. An item that elicited exactly two different names with equal frequency would have an $H$ value of 1.00 . Increasing $H$ values indicate decreasing name agreement and, generally, decreasing percentages of subjects who all gave the same name (the correlation between $H$ and percentage agreement across the set is - .94). However, the $H$ value captures more information about the distribution of names across subjects than does the percentage agreement measure. For example, if two concepts both are given their dominant name by $60 \%$ of the subjects, but one is given a single other name and the second is given four other names, both concepts will have equal percentage agreement scores, but the first will have a lower $H$ value. Accordingly, we shall use the $H$ value as the primary measure of name agreement in subsequent analyses.

Table 2 presents summary statistics for six of the measures shown in Appendix B. The 25th $(Q 1)$ and 75th $(Q 3)$ percentiles are shown to facilitate selection of concepts from the extremes of the distribution.

The distribution of $H$ values has a low mean and is positively skewed, reflecting the fact that many concepts show high name agreement $(54$ concepts have $H$ values of .0 , and 85 have $H$ values of .16 or below, where .16 represents consensus among all but one of the subjects on a 
Table 2

Summary Statistics for all the Variables

\begin{tabular}{lccccccc}
\hline & $\mathrm{H}$ & $\mathrm{IA}$ & $\mathrm{F}$ & $\mathrm{C}$ & $\mathrm{K}-\mathrm{F}$ & $\mathrm{K}-\mathrm{F}^{\prime b}$ & $\mathrm{~A}-\mathrm{A}$ \\
\hline$M$ & .558 & 3.69 & 3.29 & 2.96 & 37.86 & 2.45 & 3.09 \\
$S D$ & .526 & .585 & .956 & .897 & 88.09 & 1.59 & 1.03 \\
& & & & & & & \\
$M d n$ & .42 & 3.72 & 3.32 & 2.93 & 13 & 2.35 & 2.93 \\
$Q 1$ & .12 & 3.27 & 2.49 & 2.28 & 3 & 1.44 & 2.29 \\
$Q 3$ & .87 & 4.15 & 4.09 & 3.59 & 33 & 3.21 & 3.89 \\
$I Q R$ & .75 & .88 & 1.60 & 1.31 & 30 & 1.77 & 1.60 \\
Range & $0-$ & $2.05-$ & $1.18-$ & $1.00-$ & $0-$ & $0-$ & $1.34-$ \\
$\quad$ (limits) & 2.55 & 4.73 & 4.90 & 4.78 & 897 & 9.64 & 5.48 \\
Skew* & 1.50 & .96 & .93 & 1.02 & 2.00 & .95 & 1.50 \\
\hline
\end{tabular}

Note. $\mathrm{H}=$ name agreement $; \mathrm{IA}=$ image agreement $; \mathrm{F}=$ familiarity; $\mathrm{C}=$ visual complexity; $\mathrm{K} \cdot \mathrm{F}$ $=$ frequency; $\mathrm{K}-\mathrm{F}^{\prime}=$ transformed frequency; $\mathrm{A}-\mathrm{A}=$ age of acquisition; $Q 1=25$ th percentile; $Q 3=75$ th percentile; $I Q R=$ interquartile range.

Skew $=(Q 3-M d n) /(M d n-Q 1) ;>1$ is positively skewed.

b $K-F^{\prime}=(K-F)^{\prime}$.

picture's name). Of the three measures based on ratings, both familiarity and complexity show a greater range of values than image agreement, reflecting greater consensus among subjects on the extremes of the scale. Complexity ratings are fairly symmetric around the midpoint scale value of 3 , whereas both familiarity and image agreement ratings tend to be negatively skewed, reflecting the fact that few concepts were judged to be very low in either familiarity or image agreement. For image agreement, it is rare for subjects to agree that their visual image does not match the picture, since the lowest IA rating was 2.05 .

The Kucera-Francis frequencies are positively skewed, because of the few concepts with very high frequencies. Because we were particularly interested in the comparison between Kucera-Francis and familiarity, we sought a simple transformation of the Kucera-Francis values that would have the properties that zero frequencies be defined (which is not true of the log transform), and that the distribution of transformed scores show a negative skew comparable to that obtained for familiarity ratings. The cube root transformation $\left(\mathrm{K}-\mathrm{F}^{\prime}\right)$ met both requirements and is used in all subsequent analyses.

\section{Correlations Among the Measures}

The characteristics of pictures we chose to measure were selected for two reasons. First, they appeared to be important variables in the various semantic and episodic memory tasks in which they have been used, and second, they appeared to represent distinctly different attributes of the pictures. To determine the degree of relationship among our measures, and between them and some important measures already available, we computed the interitem correlations among all attributes presented in Appendix B (with the exception of percentage agreement). KučeraFrancis frequencies were available for only 240 of the 260 concept names-those for which the name was a single word. Because age-of-acquisition measures were available for only 89 of the concepts, a separate set of correlations was computed for this subset. Table 3 presents the matrix of significant correlations for all concepts (or for the subset of 240 for the correlations involving $\mathrm{K}-\mathrm{F}^{\prime}$ ), and Table 4 presents the matrix for the subset of items having age-of-acquisition values. With a single exception, the correlations among the four measures collected in the present study are all relatively small in magnitude, suggesting that the measures do indeed represent 
Table 3

Significant Correlations Among the Measured Variables for all 260 Concepts and Between Those Variables and Transformed KuEera-Francis Frequency for 240 Concepts

\begin{tabular}{lcrrrr}
\hline \multicolumn{1}{c}{ Variable } & 1 & 2 & 3 & 4 & 5 \\
\hline 1. Name agreement & 1.000 & & & & \\
2. Image agreement & -.313 & 1.000 & & & \\
3. Familiarity & - & .138 & 1.000 & & \\
4. Visual complexity & -130 & -.209 & -.466 & 1.000 & \\
5. Transformed frequency & - & - & .363 & -.180 & 1.000 \\
\hline
\end{tabular}

independent attributes. The single exception is the high negative correlation between familiarity and visual complexity, which we shall discuss further in some detail.

We expected that, of the measures obtained in the present study, familiarity would show the highest correlation with both frequency and age of acquisition. As shown in Tables 3 and 4, familiarity is positively correlated with frequency $(.363$ and .499 for the set of 240 and 89 concepts, respectively), although the correlations are modest in size and even smaller when the untransformed frequency values are used (.156 and .372 for the set of 240 and 89 concepts, respectively). Presumably, the reason that the correlation is so low is because frequency values do not distinguish between different meanings of a word. The fact that the correlation is higher for the subset of concepts with age-of-acquisition measures suggests that the words selected for inclusion in the age-of-acquisition norms were low in ambiguity of reference.

Familiarity is negatively correlated with age of acquisition $(-.550)$, meaning that names of concepts that are familiar also are learned at an early age. The correlation between age of acquisition and transformed frequency, although significant, is somewhat lower $(-.482)$ than that found by Carroll and White (1973a), probably because their range on both variables was greater than in the present study.

Of the correlations among our own measures, name agreement and image agreement are negatively correlated $(-.313$ and - .366), suggesting that concepts that have many names also evoke many different images. Image agreement is positively (although modestly) correlated with familiarity (.138), although the correlation is not significant for the subset of 89 concepts. Objects that are familiar tend to produce images that agree with the pictured form.

Visually complex pictures tend to have many names, tend to show low image agreement (although only for the entire set), and tend to be rated as unfamiliar. Since the visual complexity of a picture depends on how it is drawn, one interpretation of the effects of visual complexity on other attributes is that complexity is entirely a product of the whim of the artist's pen. Under this interpretation,

Table 4

Significant Correlations Among all Variables for 89 Concepts for

Which Age-of-Acquisition Norms Were Available

\begin{tabular}{|c|c|c|c|c|c|c|}
\hline Variable & 1 & 2 & 3 & 4 & 5 & 6 \\
\hline 1. Name agreement & 1.000 & 1000 & & & & \\
\hline $\begin{array}{l}\text { 2. Image agreement } \\
\text { 3. Familiarity }\end{array}$ & -.366 & 1.000 & 1.000 & & & \\
\hline 4. Visual complexity & .230 & - & -.413 & 1.000 & & \\
\hline 5. Transformed frequency & - & - & .499 & -.214 & 1.000 & \\
\hline 6. Age of acquisition & - & - & -.550 & .233 & -.482 & 1.000 \\
\hline
\end{tabular}


complexity correlates positively with $H$ because complex drawings are more difficult to recognize, negatively with image agreement because mental images are simpler than complex drawings, and negatively with familiarity because complex drawings are more novel than simple drawings.

An alternative interpretation of the effects of visual complexity is that the amount of detail in a picture is determined primarily by certain characteristics of the object itself rather than by the artist's style. We explicitly had the concepts drawn so that the amount of pictorial detail would be consistent either with the amount of detail in the real-life object or the amount of detail in its conventional representation. According to this interpretation, the two sources of the effects of visual complexity on other variables are, first, properties inherent in the object itself-how complex it is in real life-and second, properties inherent in its grammar of representation. The correlation between complexity and image agreement most likely stems from the first source, the complexity of the real-life object. That is, a complex object may be imaged in a greater variety of ways than a simple object because the former has more possible visual features than the latter. Thus, a complex object's image is less likely to match any particular pictorial representation. In contrast, the correlations of complexity with familiarity and name agreement most likely stem from the second source, the conventions developed for the concept's representation. Familiar objects, which by definition must be spoken and thought about frequently, have necessarily developed efficient and simplified verbal and visual codes. Thus, they are named briefly and consistently and pictured simply and consistently. Their simplified grammar of reference and of representation thereby accounts for the correlation between complexity and name agreement and between complexity and familiarity.

Support for the simplified visual code viewpoint is provided by data from an earlier set of 165 picture stimuli drawn by a different artist (one of the authors), for which a similar set of norms was collected (Vanderwart \& Snodgrass, Note 2). Although the 165 concepts from the previous study were a subset of the present set, their style of drawing differs considerably from the present set. Yet, the pattern of correlations between visual complexity and both familiarity and name agreement is virtually identical. Complexity was negatively correlated with familiarity, as in this study $(-.363$ vs. -.466 here $)$, and positively correlated with name agreement (.199 vs. .130 here).

\section{Naming and Imaging Failures}

Although the major purpose of the present study was not to elicit naming and imaging failures from our subjects (indeed, quite the opposite was desired), it is of interest to determine whether there is some consistency from task to task about which concepts elicited failures, and whether any of the measured characteristics of the pictures are related to such failures. Appendix C presents all concepts for which any naming or imaging difficulty occurred.

As indicated earlier, subjects in the naming task indicated, when they were unable to name a picture, whether they did not know the object, did not know the name, or were in a tip-of-the-tongue state. Subjects in the image agreement task indicated when no image had occurred, and subjects in the familiarity rating study indicated when they did not know the object pictured. The highest rate of failure occurred in the name agreement task $(1.7 \%$ across the three categories), the next highest in the image agreement task $(.7 \%)$, and the smallest in the familiarity task $(.3 \%)$. It is, of course, not surprising that the highest rate of failures occurred in naming, since subjects in that task were required to produce a name or indicate the reason why they could not. In the rating tasks, on the other hand, subjects could more easily ignore the instructions and rate the picture whether or not they recognized 
the object pictured or failed to generate an image to its name.

Because naming and imaging failures occurred so infrequently, it seemed desirable to combine responses across tasks whenever possible. Accordingly, phi coefficients were computed across similar response categories to determine whether there was significant agreement across tasks or responses about which particular concepts led to naming or imaging failures. There was significant agreement between the naming and familiarity groups as to which concepts received one or more DKO responses $(\Phi=.439)$, so the DKO responses from these two groups were combined. There was also significant agreement between concepts for which one or more DKN and TOT responses were given in the naming task $(\Phi=.400)$, so these responses were combined and all classified as TOTs. This seemed a reasonable classification, since subjects may have had difficulty discriminating between not knowing an object's name and not being able to retrieve it. Combining responses in this way produced three categories of responses: DKOs (from naming and familiarity groups); TOTs (from TOTs and DKNs in the naming groups); and NIs from the image agreement group. The intercorrelations among these three groups of responses were also significant, but lower. (For DKO versus TOT, $\Phi=.242$; for DKO versus NI, $\Phi=.163$; and for TOT versus NI, $\Phi=.290$.)

To determine on which, if any, variables the difficult-to-name or difficult-to-image concepts differed from the rest, those concepts for which either three or more subjects gave responses falling into one of the three combined categories, DKO, TOT, and NI, or whose sum on all such responses exceeded four, were identified as difficult to name/image. Twenty-nine concepts fell into this category. The 29 concepts showing high naming/imaging failures from highest incidence to lowest (concepts within parentheses are tied) are artichoke, chisel, spinning wheel, asparagus, French horn, cloud, (orange, raccoon, watering can, wrench), (nut, ostrich), (ant, peach, pea- cock, pepper, rhinoceros, rolling pin, sheep), (accordion, beetle, celery, cherry, harp, potato), and (ironing board, plug, sea horse, thimble).

The mean values for this subset of 29 on each of the four characteristics measured in the present study, and on transformed frequency values, were compared with the mean values for the remaining concepts. The subset showed significantly higher $H$ values, $t(258)=3.92$, est $\sigma_{M}$ $=.101 ;$ significantly lower familiarity ratings, $t(258)=4.82$, est $\sigma_{M}=.178 ;$ and significantly lower $\mathrm{K}-\mathrm{F}^{\prime}$ values, $t(238)$ $=3.03$, est $\sigma_{M}=.344$, whereas neither image agreement nor complexity ratings were significantly different between the two subsets.

The fact that items with higher $H$ values and lower familiarity or frequency values are more difficult to recognize, name, or image is consistent with previous research on picture-naming latencies. However, our stimuli were not purposely designed to elicit naming or imaging failures (to the contrary, in fact), so this post hoc analysis should be regarded cautiously.

\section{Sources of Name Disagreement}

To determine what kinds of names that subjects give to concepts when they disagree with the concept's dominant name, we classified nonmodal names into the following classes: synonyms, coordinates, superordinates, subordinates, and other. Synonyms included a modifier added to the basic name that was redundant with the pictured concept (e.g., green pepper for pepper and bunch of grapes for grapes). Coordinates were defined as different exemplars of the same category (e.g., spider for ant, avocado for artichoke, and antelope for deer). Superordinates included insect or bug for ant, fruit for peach, and bird for chicken. Subordinates were defined as a subclass of the concept pictured, and included polar bear for bear, sparrow for bird, and rose for flower.

Table 5 presents the results of this classification for 13 selected categories, of which 12 are the Battig and Montague 
Table 5

Percentage of Name Responses in 13 Selected Categories for (a) Dominant Responses;

(b) Synonyms; (c) Coordinates; (d) Superordinates; (e) Subordinates;

and $(f)$ Naming Failures

\begin{tabular}{lccccccc}
\hline \multicolumn{1}{c}{ Category } & $\begin{array}{c}(\mathrm{a}) \\
\text { Dom }\end{array}$ & $\begin{array}{c}\text { (b) } \\
\text { Syn }\end{array}$ & $(\mathrm{a}+\mathrm{b})$ & $\begin{array}{c}\text { (c) } \\
\text { Coord }\end{array}$ & $\begin{array}{c}\text { (d) } \\
\text { Super }\end{array}$ & $\begin{array}{c}\text { (e) } \\
\text { Sub }\end{array}$ & $\begin{array}{c}\text { (f) } \\
\text { Fail }\end{array}$ \\
\hline Insects (8) & 76 & 0 & 76 & 11 & 9 & 0 & 4 \\
Musical instruments (9) & 85 & 0 & 85 & 6 & 2 & 2 & 4 \\
Vegetables (13) & 83 & 4 & 87 & 5 & 1 & 0 & 6 \\
Birds (8) & 84 & 4 & 88 & 8 & 2 & 0 & 3 \\
Carpenter's tools (12) & 87 & 2 & 89 & 6 & 0 & 0 & 5 \\
Clothing (19) & 89 & 3 & 92 & 5 & 1 & 2 & 0 \\
Fruits (11) & 91 & 1 & 92 & 3 & 1 & 0 & 4 \\
Animals (30) & 90 & 3 & 93 & 5 & 0 & 0 & 2 \\
Kitchen utensils (14) & 85 & 9 & 94 & 1 & 3 & 1 & 1 \\
Basic level (4) & 95 & 0 & 95 & 0 & 0 & 5 & 0 \\
Vehicles (10) & 85 & 13 & 98 & 0 & 0 & 2 & 0 \\
Human body parts (12) & 88 & 10 & 98 & 0 & 0 & 2 & 0 \\
Furniture (14) & 84 & 15 & 99 & 1 & 1 & 0 & 0 \\
\hline
\end{tabular}

Number of exemplars in each category are in parentheses.

categories. All exemplars listed in Table 1 are included except those for which the pictured form of the concept is judged to differ from the meaning intended (marked with a dagger in Table 1) or in which an exemplar appears in another category with higher frequency (marked with an asterisk in Table 1). Three of the Battig and Montague categories are omitted either because of the small number of exemplars in each or because so many of the pictured concepts were not the meaning intended. These omitted categories are weapons, building parts, and toys. An additional category has been added to Table 5 , the basic level category consisting of the concepts bird, fish, flower, and tree.

Of particular interest in Table 5 is the column labeled $(a+b)$, which represents the total percentage of dominant and synonymous names in each category and thus can be considered to be the percentage of correct names for the concept. Percentage of correct names varies from a low of $76 \%$ for the insect category to a high of $99 \%$ for the furniture category.

The categories differ by the kinds of incorrect names given, with insects eliciting a high percentage of coordinates and superordinates, vegetables eliciting a high percentage of naming failures, and the basic level category the only one to show any appreciable number of subordinate responses (although these occurred exclusively for the concepts of bird and flower).

\section{Concept Versus Name Agreement}

As we indicated previously, the criterion for defining name agreement was very strict. In particular, such synonymous terms as TV for television and purse for pocketbook were treated as separate name categories in computing both $H$ and percentage agreement. Although this definition of name agreement is useful as a measure for predicting such cognitive tasks as naming latencies, it is less useful for such tasks as picture recall, in which synonyms for the dominant name would probably be scored as correct responses.

Accordingly, we have identified concepts whose high values of $H$ reflect linguistic ambiguity, as opposed to conceptual or pictorial ambiguity. As we use the term, linguistically ambiguous items are those that elicit a variety of names that are approximately synonymous and thus may be said to have high concept, as opposed to name, agreement. 
Table 6

Items of High Concept Agreement and Low Name Agreement

\begin{tabular}{|c|c|c|c|}
\hline $\begin{array}{c}\text { Identifying } \\
\text { no. }\end{array}$ & Name & $\begin{array}{l}\% \text { Concept } \\
\text { agreement }\end{array}$ & $\begin{array}{l}\text { Synonyms } \\
\text { (in order of frequency) }\end{array}$ \\
\hline 2 & Airplane & 88 & Plane, jet \\
\hline 13 & Baby carriage & 98 & Carriage \\
\hline 17 & Barn & 90 & Barn and Silo \\
\hline 19 & Baseball bat & 100 & Bat \\
\hline 29 & Blouse & 90 & Shirt, jacket \\
\hline 33 & Bow & 95 & Ribbon, bow tie \\
\hline 47 & $\mathrm{Car}$ & 90 & Lincoln \\
\hline 55 & Chicken & 90 & Hen \\
\hline 71 & Deer & 83 & Antelope \\
\hline 74 & Doll & 93 & Baby, little girl \\
\hline 79 & Dresser & 90 & $\begin{array}{l}\text { Bureau, chest, } \\
\text { chest of drawers, drawers }\end{array}$ \\
\hline 88 & Finger & 88 & Index finger \\
\hline 98 & Fox & 88 & Wolf \\
\hline 101 & Frying pan & 95 & Pan \\
\hline 105 & Glasses & 98 & Eye glasses \\
\hline 112 & Gun & 100 & Pistol, revolver \\
\hline 127 & Kettle & 98 & Tea kettle, teapot \\
\hline 134 & Leg & 88 & Knee \\
\hline 136 & Leopard & 86 & Tiger \\
\hline 146 & Moon & 95 & $\begin{array}{l}\text { Quarter moon, crescent } \\
\text { moon, half moon }\end{array}$ \\
\hline 152 & Nail file & 98 & File \\
\hline 153 & Necklace & 93 & Pearl necklace, beads, pearls \\
\hline 161 & Paintbrush & 95 & Brush \\
\hline 178 & Pocketbook & 90 & Handbag, purse \\
\hline 184 & Record player & 90 & Phonograph, turntable \\
\hline 189 & Roller skate & 100 & Skate \\
\hline 191 & Rooster & 88 & Chicken \\
\hline 214 & Spool of thread & 98 & Thread, spool \\
\hline 219 & Stove & 98 & Oven, range \\
\hline 221 & Suitcase & 90 & Luggage \\
\hline 228 & Television & 100 & TV, television set \\
\hline 235 & Toe & 95 & Big toe, toes \\
\hline 239 & Traffic light & 90 & Stop light \\
\hline 243 & Trumpet & 90 & Horn \\
\hline 258 & Wine glass & 100 & Glass, goblet \\
\hline
\end{tabular}

High concept agreement pictures were defined as those items whose $H$ values were greater than or equal to 1.00 and for which three or fewer subjects gave names that were not synonyms of the dominant name. Of the 48 concepts having $H$ values of 1.00 or greater, 35 fulfilled the criterion of high concept agreement. These concepts are listed in Table 6, along with the recomputed percentage agreement score when all synonyms are considered equivalent to the dominant name. The table also lists the synonyms in order of the frequency with which three or more subjects gave them as responses. Names were classified as synonyms on the basis of the experimenters' judgment and with respect to the picture's appearance. Thus, the name baby was considered reasonably synonymous with the pictured doll, although it would not have been had a rag-type doll been pictured. In any case, the information provided in Appendix $\mathrm{C}$ is sufficiently detailed to permit an investigator to recalculate the data shown in Table 6 . The average percentage con- 
cept agreement score is $93 \%$ for these 35 concepts compared to the average of $64 \%$ name agreement.

\section{Supplementary Image Agreement Measures}

There were two subsidiary image agreement measures obtained for the set of pictures: picture-naming agreement, obtained by having subjects judge the degree to which a presented picture matched its name, and image variability, obtained by having subjects rate how many different images a name could have in the absence of the picture. These supplementary measures were obtained to clarify the data on image agreement, which seems to be the most subjective judgment of all the measures. We expected the correlation between image agreement and picture-name agreement to be high and positive, and the correlation between image agreement and image variability to be lower and negative.

Picture-name agreement. As expected, the correlation between image agreement and picture-name agreement was highly significant across the 260 picture-name pairs $(r=.739)$, suggesting that the process subjects used to decide whether an image generated to a name agreed with a picture was not much different from that used to decide whether a name agreed with a picture. However, the mean ratings were significantly higher for picture-name agreement than for image agreement, $t(259)$ $=9.20$, est $\sigma_{M}=.036$, either because the picture immediately clarifies the meaning of the name or because the presence of the picture biases the subject toward the particular appearance of the object shown. Obviously, subjects must access some information in long-term memory about how objects look in order to make picture-name agreement judgments, even though they may not actually form a mental image to decide that a picture matches its name.

Image variability. The correlation between image agreement and image variability was negative and lower, as expected $(r=-.441)$. Our expectation that the two measures should be negatively correlated was based on the notion that a mismatch between a particular subject's image of an object and its picture in the image agreement task is diagnostic of the possibility that a particular concept can have many different images. Conversely, if a subject can create many different and different-appearing images for a concept, that concept's picture is less likely to match any one of his or her images. For example, such concepts as artichoke, lemon, and zebra, which were rated lowest on image variability, are examples of concepts that look very similar from instance to instance, whereas car, dog, dress, and house, which were rated highest on image variability, are examples of concepts that look very different from instance to instance. Interestingly, all four of the basic level concepts, bird, fish, flower, and tree, had image variability ratings in the upper $4 \%$ of the distribution.

\section{Significance of the Normative Data for Future Research}

The intercorrelations among name agreement, familiarity, visual complexity, and image agreement are quite low, suggesting that the four measures represent largely independent attributes of the pictures. It will be useful to consider the possible effects of these attributes with regard to five experimental paradigms widely used in studies of picture-word processing. The first two are semantic memory processing tasks, and the remaining three are episodic memory tasks. The semantic memory tasks are picture naming, in which the latency to name a pictured object is measured, and picture categorization, in which the latency to classify an object into its semantic category is measured. The episodic memory tasks include two types of recognition memory tasks as well as the classical free-recall task. The two recognition memory tasks are stimulus recognition, in which the form of the item (picture or word) is the same in the test as it is in the study presentation, and concept recognition, in which the study and test forms of the item are different, for example, a picture study item is tested as a word and vice versa. 
Table 7

Means of the Battig and Montague Ranks, Familiarity Ratings, and Complexity Ratings of Relevant Exemplars of 12 of the Battig and Montague Categories, With the Correlation Between Rank and Familiarity Within Each Category

\begin{tabular}{lcccc}
\hline \multicolumn{1}{c}{ Category (n)a } & Rank & Familiarity & $r$ & Complexity \\
\hline Fruits (11) & 7.6 & 3.36 & $-.642^{*}$ & 2.31 \\
Insects (8) & 7.7 & 2.44 & -.502 & 4.04 \\
Musical instruments (9) & 8.4 & 2.60 & $-.611^{*}$ & 4.04 \\
Human body parts (12) & 12.0 & 4.66 & -.198 & 2.42 \\
Carpenter's tools (12) & 11.3 & 3.23 & -.120 & 2.37 \\
Vehicles (10) & 12.5 & 3.58 & $-.904^{* *}$ & 3.81 \\
Clothing (19) & 15.8 & 3.92 & $-.395^{*}$ & 2.61 \\
Vegetables (13) & 18.9 & 3.18 & $-.623^{*}$ & 3.03 \\
Kitchen utensils (14) & 20.5 & 4.16 & $-.513^{*}$ & 2.26 \\
Furniture (14) & 23.8 & 4.10 & $-.515^{*}$ & 2.66 \\
Animals (30) & 24.0 & 2.36 & $-.305^{*}$ & 3.84 \\
Birds (8) & 29.7 & 2.16 & -.473 & 3.82 \\
$M$ & & & & \\
$M$ & 16.0 & 3.31 & -.483 & 3.10 \\
\hline
\end{tabular}

Number of exemplars per category in parentheses.

$* p<.05 .{ }^{* *} p<.01$.

\section{Name Agreement}

The variable of name agreement is likely to affect naming latencies for pictures. The results of Lachman (1973) would lead us to expect that concepts with high $H$ values will have longer naming latencies than concepts with low $H$ values. However, we would not expect name agreement to affect categorization times for pictures if, as is commonly believed, subjects categorize a picture without first accessing the name. Thus, for example, pictures from the insect category, many of which are difficult to name, should be as quickly categorized as pictures from the furniture or clothing category, most of which are easy to name.

Similarly, name agreement is unlikely to influence stimulus recognition memory to any great extent, since picture recognition appears to be mediated largely by visual rather than by verbal codes (Nelson et al., 1976; Paivio, 1971; Snodgrass, Burns, \& Pirone, 1978). On the other hand, in a concept recognition task, name agreement should be a relevant variable, since a picture with many possible names will have a verbal code that is unlikely to match the experimenter-determined name. Accordingly, concepts with high name agreement will be better recognized than concepts with low name agreement in a concept recognition memory paradigm.

In a recall task, it is obvious that name agreement will affect recall of pictures, since recall requires retrieving the name of the concept. Pictures that have high $H$ values either are named with difficulty or have many synonymous names. Pictures that are named with difficulty will probably be recalled less well, although pictures with many synonymous names may be recalled as well as pictures with unique names. Table 6 provides information necessary to distinguish these two classes of high $H$ value pictures and also lists the synonyms that are likely to appear as "correct" recall responses.

\section{Familiarity}

The familiarity rating of a picture is analogous to the frequency count of the word form of the concept, and the two are highly correlated. It is well-known that an inverse relation exists between naming latency and the frequency of the picture's name. Thus we would expect pictures with low familiarity to have longer naming latencies than pictures with high familiarity. The form of the famili- 
arity function may be somewhat different from the frequency function because the frequency count includes all the meanings of the word form.

Category judgments are made more quickly for concepts that are prototypical of their category, in the Roschian sense. Accordingly, if familiarity and prototypicality are correlated, then it follows that familiar concepts will also be categorized more quickly. It seems likely that when typicality is defined as the frequency with which the name of an exemplar is retrieved from semantic memory (as we have done for the Battig and Montague categories), more familiar concepts should be retrieved more readily, and hence have a higher rank than unfamiliar concepts.

To investigate the relation between typicality and familiarity, we computed correlations between rank and familiarity for 12 of the Battig and Montague categories (using the same criteria for exemplar inclusion employed for Table 5). Table 7 presents the correlations for each of the 12 categories, with the mean ranks and familiarity ratings by category. (The mean complexity ratings by category are also shown and will be discussed.)

Eight of the 12 correlations are significant and negative, indicating that highly ranked items (those with low numerical ranks) also tend to be more familiar. The mean of the 12 correlations $(-.483)$ is also significantly different from zero by a $t$ test, $t(11)=7.91$, est $\sigma_{M}=.061$. Thus, the hypothesis that typical category exemplars are also more familiar is confirmed, and hence we expect that familiar pictures will be categorized faster than unfamiliar pictures.

Table 7 also reveals that the category exemplars vary in familiarity, from a low of 2.16 for the bird category to a high of 4.66 for the category of human body parts. Some of this variation is a result of selection of the exemplars (e.g., all of our birds are quite atypical). A considerable amount of variation, however, is due to the nature of the category itself. An analysis of variance performed on the 12 mean familiarity values was highly signifi- cant, $F(11,148)=25.71, \quad M S_{\mathrm{e}}=.343$. A Newman-Keuls test revealed five groups of categories that were significantly different from one another. They are, in order from lowest familiarity to highest familiarity, (a) birds, animals, insects, musical instruments; (b) vegetables, carpenter's tools; (c) fruits, vehicles, clothing ; (d) furniture, kitchen utensils; and (e) human body parts.

We would expect picture familiarity to affect episodic memory in much the same way as word frequency does. Specifically, the recognition-recall paradox for wordsthat frequent words are better recalled than recognized and infrequent words better recognized than recalled-should also hold for familiar and unfamiliar pictures. As we have noted, familiarity is a "purer" measure of the picturable sense of a word than frequency. Thus, familiarity should be a better predictor of memory performance for pictures and for words in which the experimental context biases a particular word meaning. For example, the concept recognition task, in which words are tested with their picture form, presumably biases word interpretation toward its picturable noun sense, and a categorized list recall task presumably biases word interpretation toward the sense relevant to the category (e.g., nut as a tool vs. as a vegetable).

\section{Visual Complexity}

The complexity of a picture primarily reflects the superficial visual characteristics of the object and its conventions of pictorial representation. The picture-naming task presumably requires at least two steps: picture recognition and name retrieval. The first step of picture recognition may take longer for more complex pictures, so that visual complexity may affect naming latencies.

Similarly, categorization also requires picture recognition as a first step, although the process of name finding may be bypassed. Pictures that vary in complexity within a category may show corresponding variations in categorization latencies. Fur- 
thermore, the extent to which categories as a whole differ in complexity should affect categorization times between categories. Table 7 shows considerable variation in mean complexity from category to category, with the categories of kitchen utensils and fruits having relatively simple exemplars, and the categories of insects and musical instruments having relatively complex exemplars. An analysis of variance revealed that the 12 categories did indeed vary significantly in complexity, $F(11,148)$ $=20.63, M S_{\mathrm{e}}=.339$. A Neuman-Keuls test revealed that three groups of categories were significantly different from one another. They are, in order from lowest complexity to highest complexity, (a) kitchen utensils, fruits, carpenter's tools, human body parts, clothing, and furniture; (b) vegetables; and (c) vehicles, birds, animals, musical instruments, and insects.

In episodic memory tasks, visual complexity may affect stimulus recognition memory. The intricate detail in a complex picture (e.g., motorcycle) or utter lack of it in a simple picture (e.g., star) may function to make the stimulus novel and thus more recognizable than medium complex pictures. Some effect of complexity may also obtain in a concept recognition task. One might speculate that mental image codes generated to the word form of a concept are relatively simple and schematic. Thus, a very complex object presented first in word form and tested in picture form would be less well recognized than a simple object because its schematic image would not provide as good a match to its detailed picture. In general, complexity should have its greatest effects in recognition rather than recall.

Nelson et al. (1976) have shown that visual or schematic similarity among a set of pictures reduces the picture superiority effect in paired-associate recall, when pictures are the stimulus members. Visual complexity is different from similarity in that the former refers to an aspect of individual pictures, whereas the latter refers to a characteristic shared by two or more pictures. However, the extent to which objects can be visually similar presumably depends on their overall level of complexity, with simpler objects (e.g., ball, balloon, apple) having more opportunity for visual similarity than complex objects. Thus, complexity probably also affects the degree to which the picture superiority effect can be reduced by introducing visual similarity.

\section{Image Agreement}

Image agreement will be likely to influence semantic tasks in some interesting ways. As we just noted, the picturenaming process presumably entails two subprocesses: First, the image code corresponding to the picture must be accessed (i.e., the object must be recognized for what it is), and then the verbal label must be accessed. The time consumed by the second step, name finding, may be held constant by selecting items of the same degree of name agreement and familiarity. The first step, image finding, however, is presumably directly dependent on image agreement. A picture with low image agreement would take longer to name because its corresponding image would take longer to identify. To date, we have unfortunately not been able to analyze naming latencies in such a fashion due to the unavailability of image agreement norms.

In categorization tasks, image agreement may act in a way analogous to prototypicality. The prototypicality of a concept as an exemplar of its class is a prime determiner of superordinate category judgment latencies. Image agreement is an analogous measure to prototypicality on the basic category level. That is, image agreement measures the typicality of the form of the exemplar-it answers the question, How good an exemplar is the picture of the concept it represents? Accordingly, pictures with high image agreement should be categorized faster than pictures with low image agreement, just as typical exemplars are categorized faster than atypical exemplars.

As in the case of complexity, image agreement is more relevant theoretically 
to recognition memory than to recall memory. In stimulus recognition, pictures with low image agreement should be at a disadvantage because they are less likely to access a strong image code or will conflict with the memory code stored for that concept. However, the effects of image agreement should be more noticeable in the concept recognition task. Here, for a low image agreement item, if a subject receives the word form first, he or she is less likely to generate an image that agrees with the picture presented in the test. Thus, low image agreement should produce poor recognition when items are given as words in the study and as pictures in the test.

In summary, we have presented an extensive set of pictures whose properties have been quantified on several variables of theoretical importance to memory and perception. It is our hope that investigators will take advantage of this standardized set in future research, so that theoretical questions about differences in processing between pictures and words may be investigated in the absence of potential artifacts attributable to peculiar, and unmeasured, aspects of pictorial stimuli.

\section{Reference Notes}

1. Snodgrass, J. G. Toward a model for picture and word processing. Paper presented at the Second Conference on Processing of Visible Language, Niagara-on-the-Lake, Canada, September 1979.

2. Vanderwart, M., \& Snodgrass, J. G. A new set of 165 picture stimuli with norms for naming ambiguity, visual complexity, familiarity, and prototypicality. Unpublished manuscript, 1977. (Available from J. G. Snodgrass, Department of Psychology, New York University, 6 Washington Place, New York, New York 10003.)

\section{References}

Anderson, J. R., \& Bower, G. H. A propositional theory of recognition memory. Memory \& Cognition, 1974, 2, 406-412.

Battig, W. F., \& Montague, W. E. Category norms for verbal items in 56 categories: A replication and extension of the Connecticut category norms. Journal of Experimental Psychology Monograph, 1969, 80 (3, Pt. 4).
Bousfield, W. A., Esterson, J., \& Whitmarsh, G. A. The effects of concomitant colored and uncolored pictorial representations on the learning of stimulus words. Journal of Applied Psychology, $1957,41,165-168$.

Brown, A. S. Catalog of scaled verbal material. Memory \& Cognition, 1976, 4, 1S-45S.

Carroll, J. B., \& White, M. N. Age-of-acquisition norms for 220 picturable nouns. Journal of Verbal Learning and Verbal Behavior, 1973, 12, 563-576. (a)

Carroll, J. B., \& White, M. N. Word frequency and age of acquisition as determiners of picturenaming latency. Quarterly Journal of Experimental Psychology, 1973, 25, 85-95. (b)

Cattell, J. M. The time it takes to see and name objects. Mind, 1886, 11, 63-65.

Durso, F. T., \& Johnson, M. Facilitation in naming and categorizing repeated pictures and words. Journal of Experimental Psychology: Human Learning and Memory, 1979, 5, 449-459.

Fraisse, P. Recognition time measured by verbal reaction to figures and words. Perceptual \& Motor Skills, 1960, 11, 204.

Intraub, $H$. The role of implicit naming in pictorial encoding. Journal of Experimental Psychology: Human Learning and Memory, 1979, 5, 78-87.

Kučera, H., \& Francis, W. N. Computational analysis of present-day American English. Providence, R.I.: Brown University Press, 1967.

Lachman, $R$. Uncertainty effects on time to access the internal lexicon. Journal of Experimental Psychology, 1973, 99, 199-208.

Martin, E. Generation-recognition theory and the encoding specificity principle. Psychological Review, 1975, 82, 150-153.

Nelson, D. L., Reed, V. S., \& McEvoy, C. L. Learning to order pictures and words: A model of sensory and semantic encoding. Journal of Experimental Psychology: Human Learning and Memory, 1977, 3, 485-497.

Nelson, D. L., Reed, V. S., \& Walling, J. R. Pictorial superiority effect. Journal of Experimental Psychology: Human Learning and Memory, $1976,2,523-528$.

Nickerson, R. S. Short-term memory for complex meaningful visual configurations: A demonstration of capacity. Canadian Journal of Psychology, $1965,19,155-160$.

Oldfield, R. C., \& Wingfield, A. Response latencies in naming objects. Quarterly Journal of Experimental Psychology, 1965, 17, 273-281.

Paivio, A. Imagery and verbal processes. New York: Holt, Rinehart, \& Winston, 1971.

Paivio, A. Mental comparisons involving abstract attributes. Memory \& Cognition, 1978, 6, 199-208.

Paivio, A., \& Csapo, K. Picture superiority in free recall: Imagery or dual coding? Cognitive $P$ sychology, 1973, 5, 176-206.

Paivio, A., Rogers, T. B., \& Smythe, P. C. Why are pictures easier to recall than words? Psychonomic Science, 1968, 11, 137-138. 
Pellegrino, J. W., Rosinski, R. R., Chiesi, H. L., \& Siegel, A. Picture-word differences in decision latency: An analysis of single and dual memory models. Memory \& Cognition, 1977, 5, 383-396.

Potter, M. C., \& Faulconer, B. A. Time to understand pictures and words. Nature, 1975, 253, 437-438.

Potter, M. C., Valian, V. V., \& Faulconer, B. A. Representation of a sentence and its pragmatic implications: Verbal, imagistic, or abstract? Journal of Verbal Learning and Verbal Behavior, 1977, 16, 1-12.

Reder, L. M., Anderson, J. R., \& Bjork, R. A. A semantic interpretation of encoding specificity. Journal of Experimental Psychology, 1974, 102, 648-656.

Rosch, E., Mervis, C. B., Gray, W. D., Johnson, D. M., \& Boyes-Braem, P. Basic objects in natural categories. Cognitive Psychology, 1976, 8, 382-439.

Shepard, R. N. Recognition memory for words, sentences, and pictures. Journal of Verbal Learning and Verbal Behavior, 1967, 6, 156-163.

Smith, M. C., \& Magee, L. E. Tracing the time course of picture-word processing. Journal of Experimental Psychology: General, in press.

Snodgrass, J. G., Burns, P. M.. \& Pirone. G. V.
Pictures and words and space and time: In search of the elusive interaction. Journal of $E x$ perimental Psychology: General, 1978, 107, 206230.

Snodgrass, J. G., \& McClure, P. Storage and retrieval properties of dual codes for pictures and words in recognition memory. Journal of Experimental Psychology: Human Learning and Memory, 1975, 1, 521-529.

Snodgrass, J. G., Wasser, B., Finkelstein, M., \& Goldberg, L. B. On the fate of visual and verbal memory codes for pictures and words: Evidence for a dual coding mechanism in recognition memory. Journal of Verbal Learning and Verbal Behavior, 1974, 13, 27-37.

Standing, L., Conezio, J., \& Haber, R. N. Perception and memory for pictures: Single-trial learning of 2,560 visual stimuli. Psychonomic Science, 1970, 19, 73-74.

Tulving, E. Episodic and semantic memory. In E. Tulving \& W. Donaldson (Eds.), Organization of memory. New York: Academic Press, 1972.

Tulving, E., \& Thomson, D. M. Retrieval processes in recognition memory: Effects of associative context. Journal of Experimental Psychology, 1971, 87, 116-124.

Index to Appendixes

$\begin{array}{cc}\text { Appendix } & \text { Page } \\ \text { A } & 197 \\ \text { B } & 205 \\ \text { C } & 210\end{array}$


Appendix A

The 260 pictures are shown below with their identifying number. They are arranged in alphabetical order according to each picture's most common name. The names of each picture and their norms are shown in Appendix B with the identifying numbers.
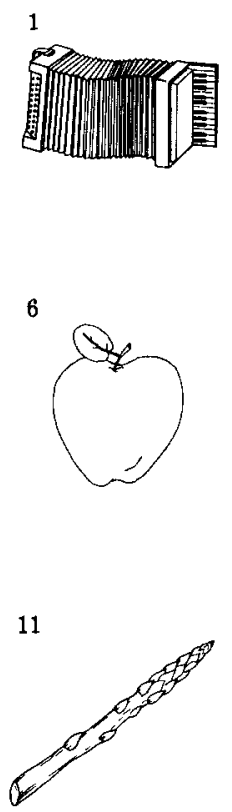

16

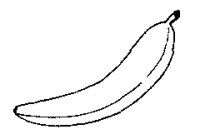

21

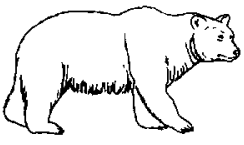

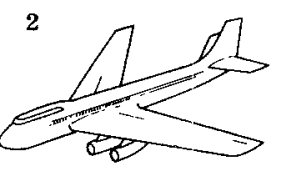

7

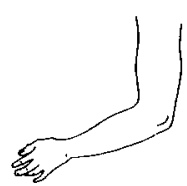

12

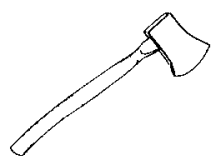

17

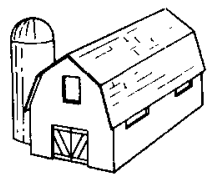

3

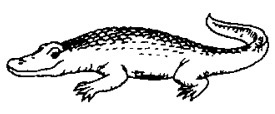

8

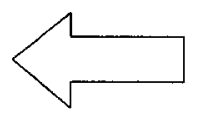

13

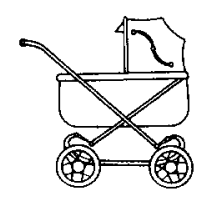

18

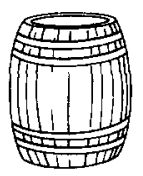

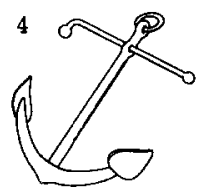

5

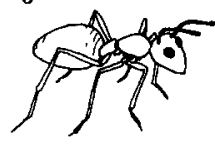

9

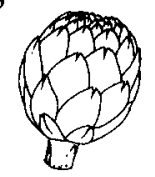

14

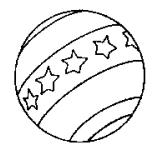

19
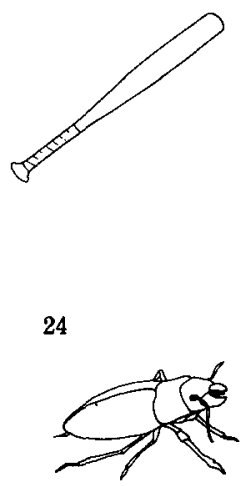

20

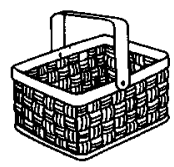

25

10

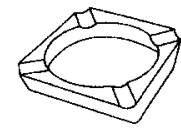

15
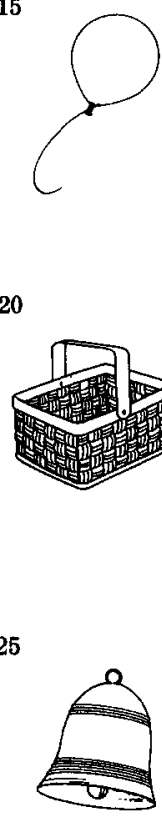

26

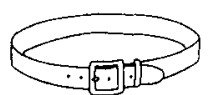

22

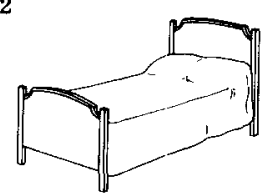

27

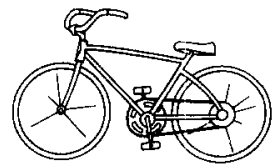

23

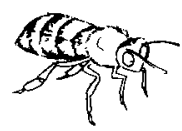

28

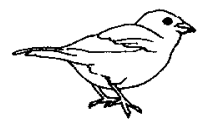

29

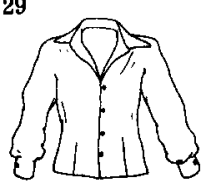

30

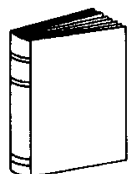


31

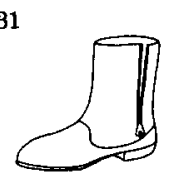

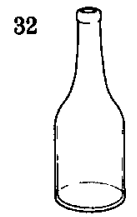

37

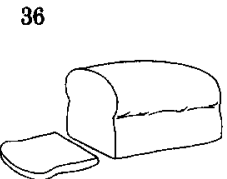

33

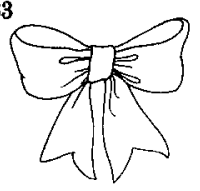

34

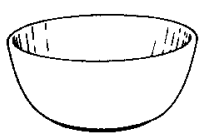

35

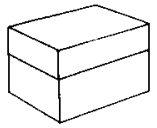

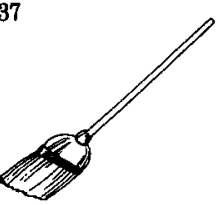

38

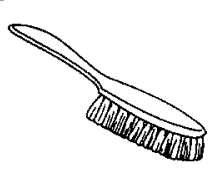

43

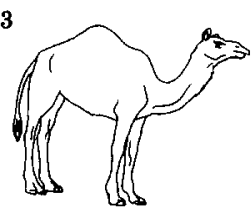

48

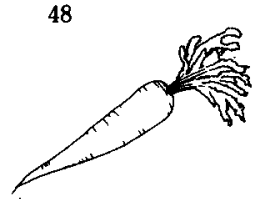

53

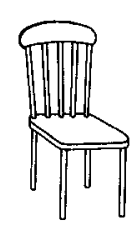

57

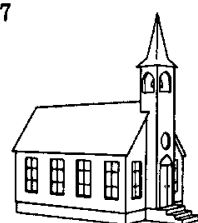

52

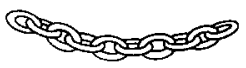
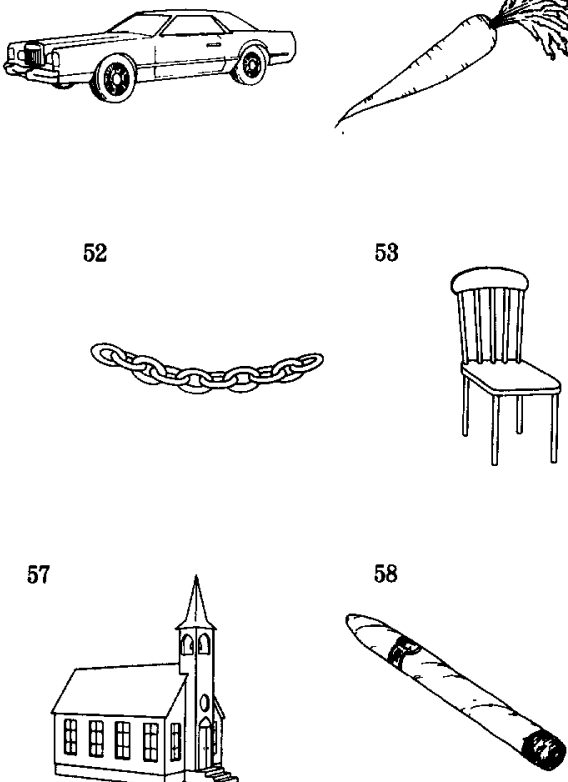

63

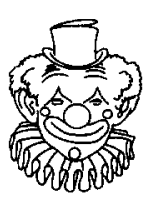

62

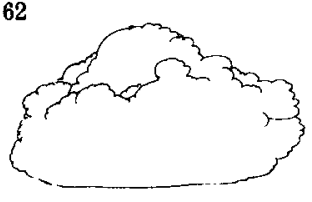

63
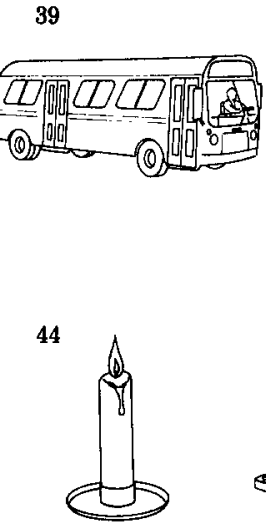

40

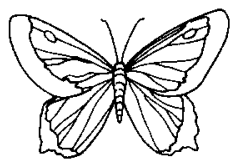

50

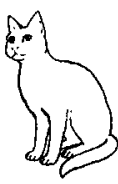

45

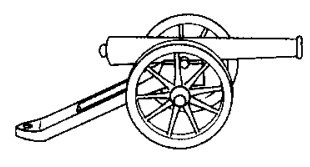

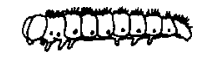

54

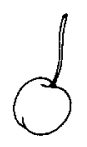

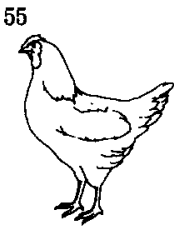

59
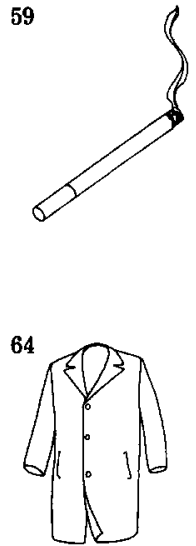

60

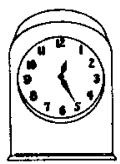

61

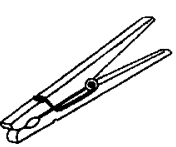



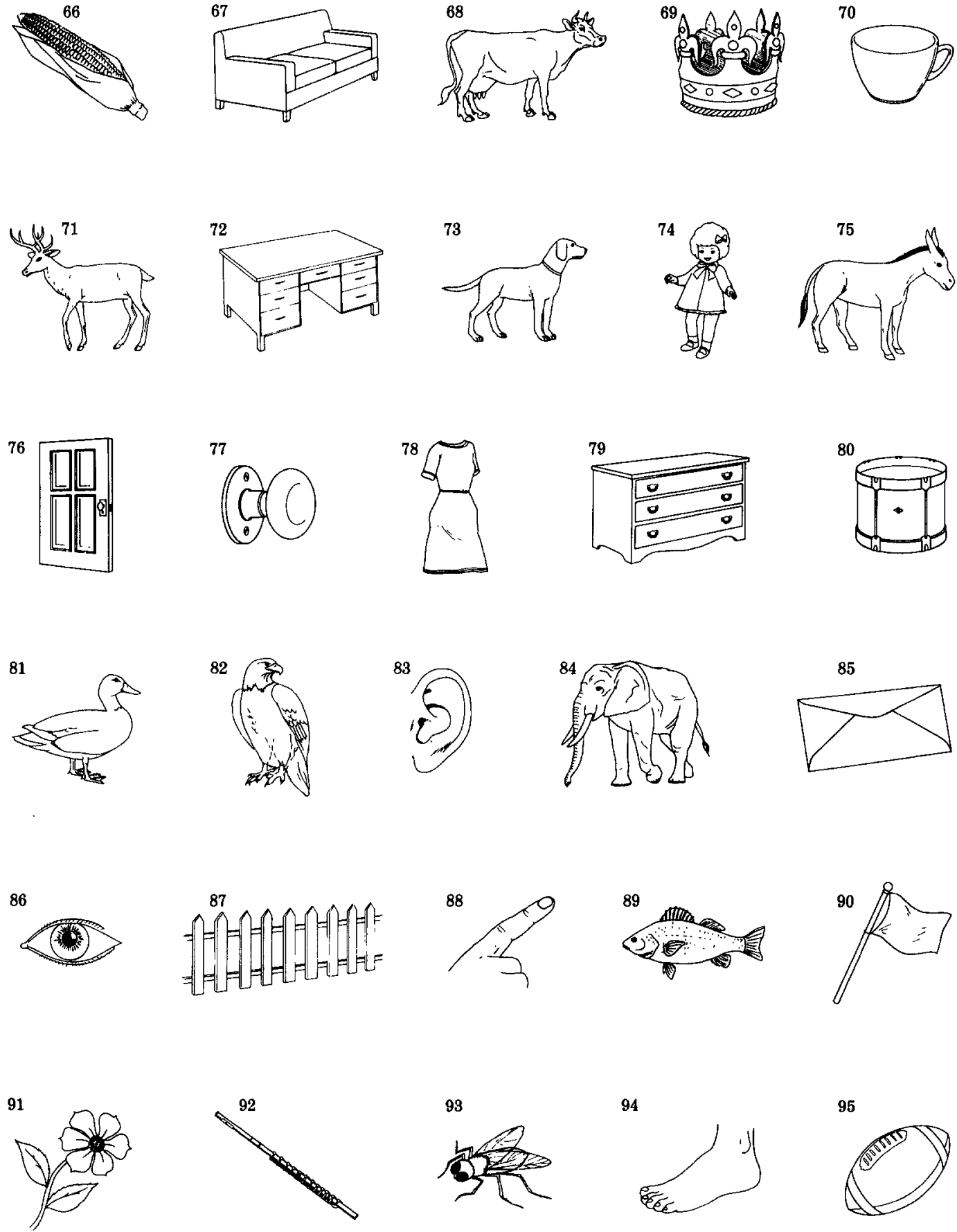

94
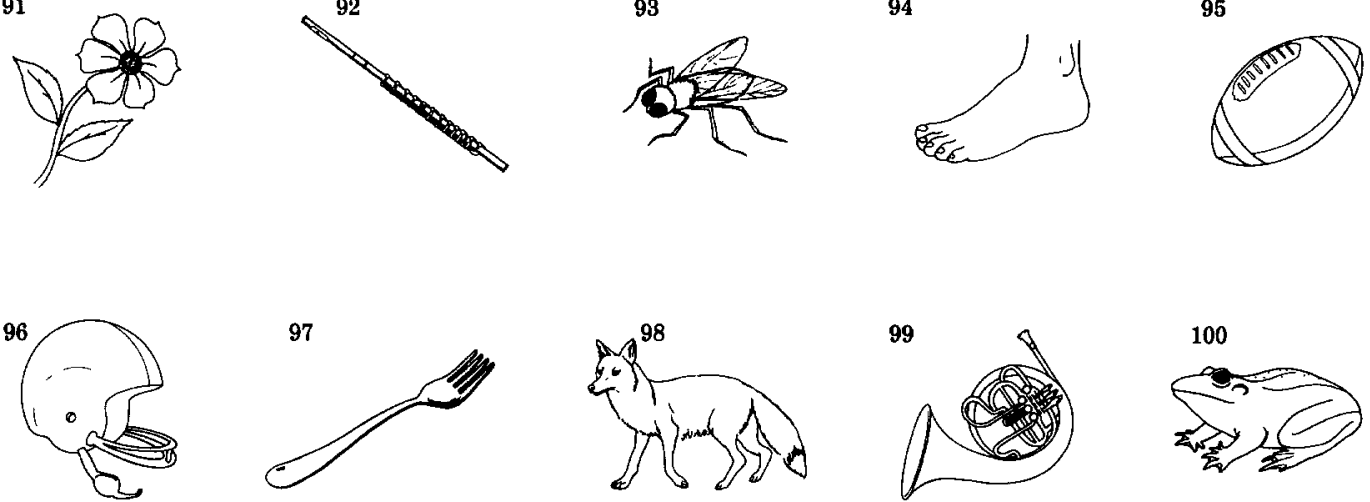


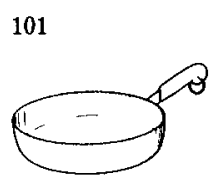

102

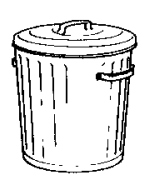

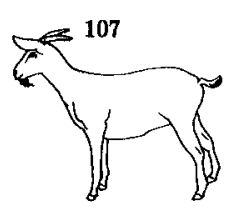
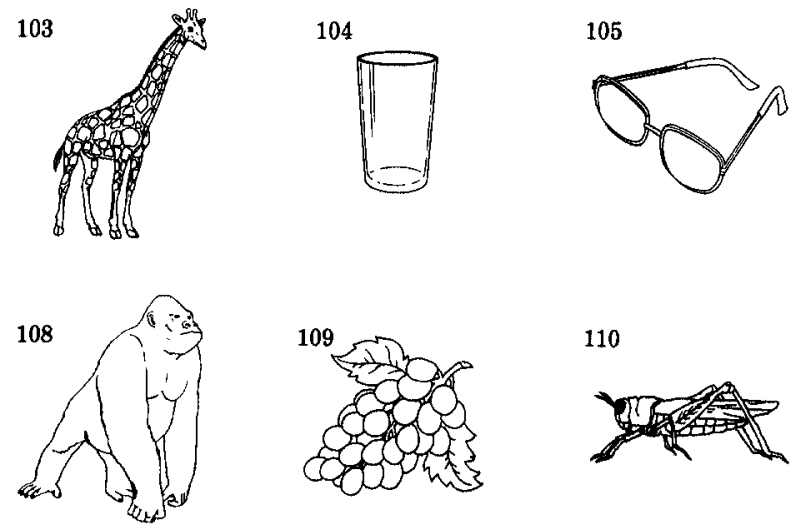

110
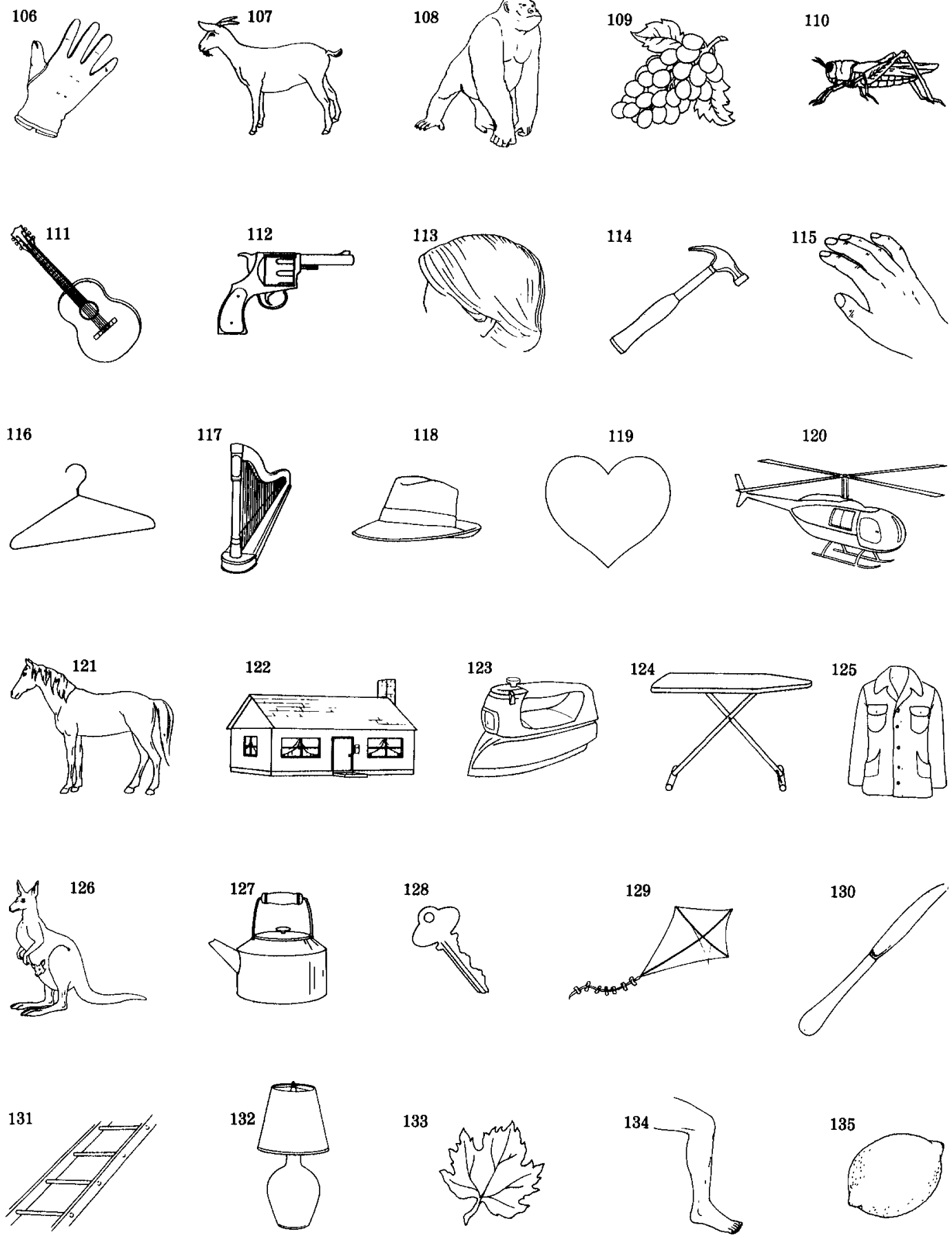

133

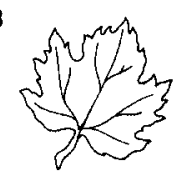

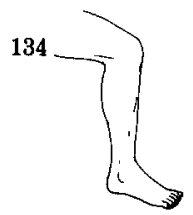

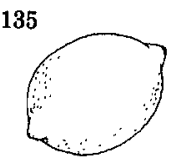



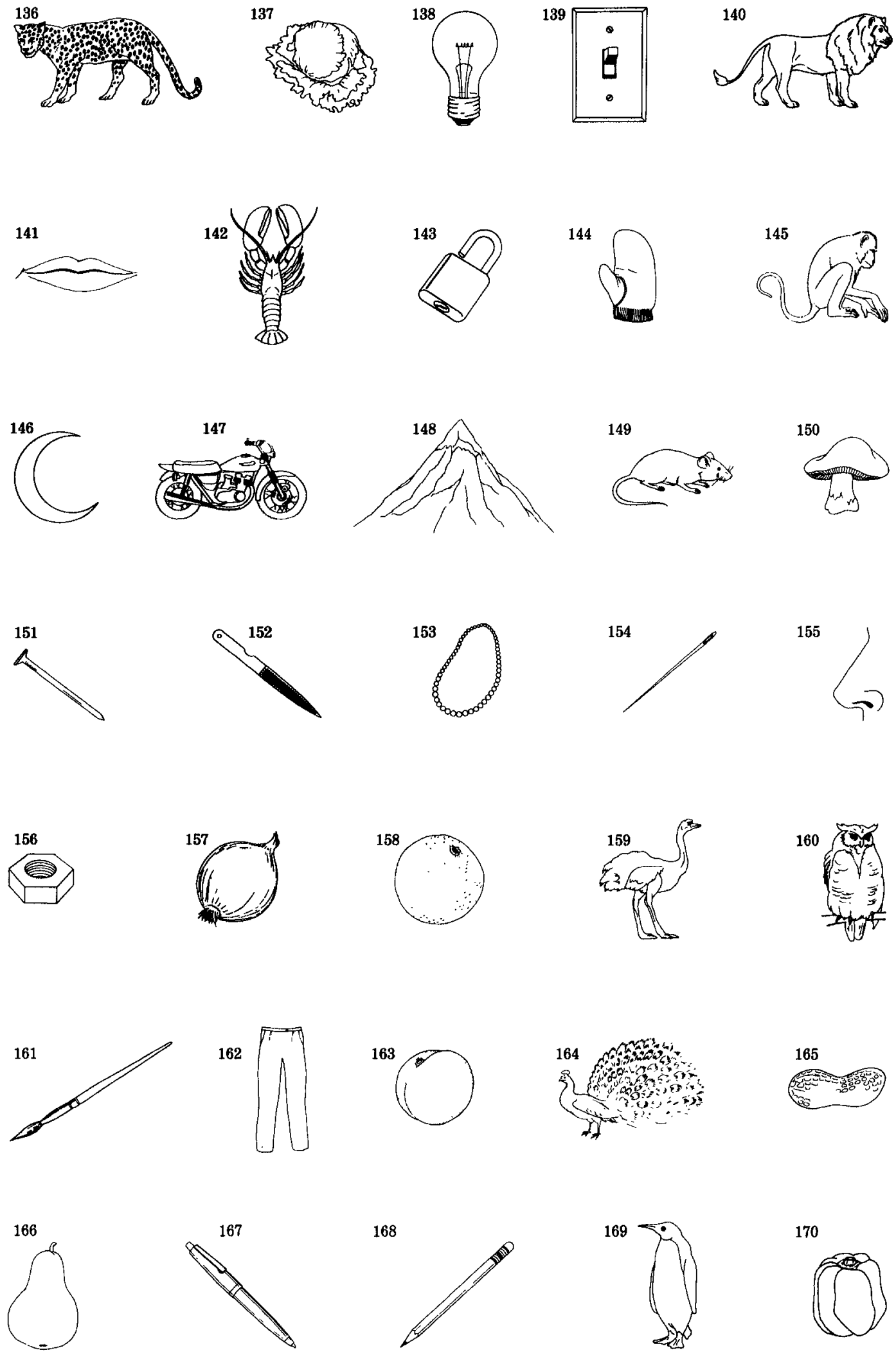


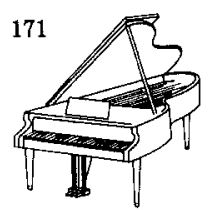

172

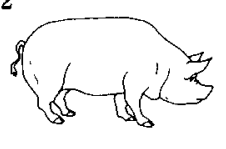

173

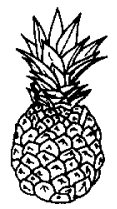

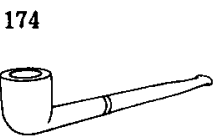

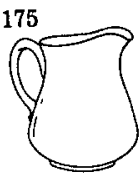

179
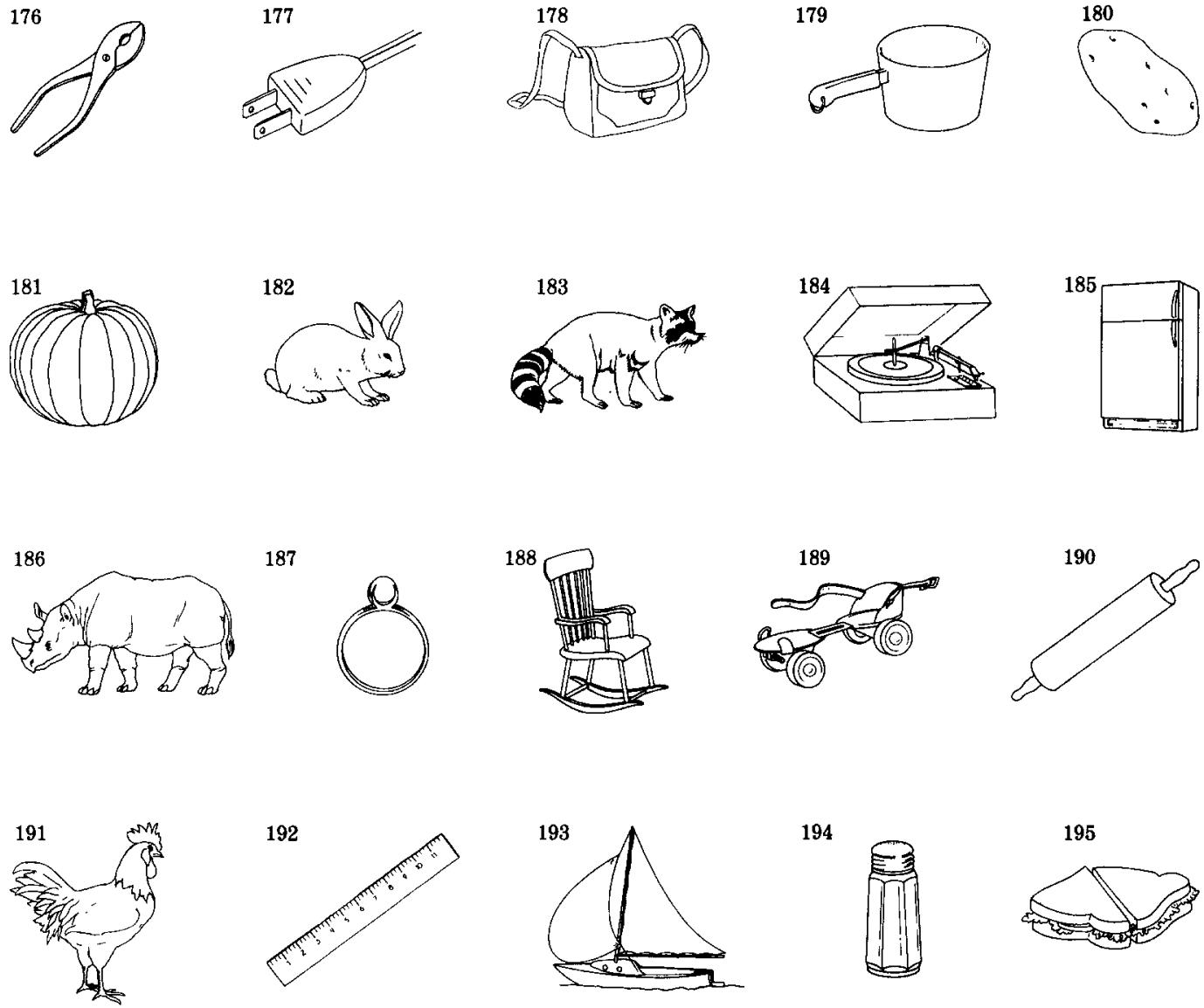

194

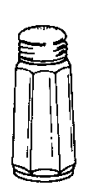

195

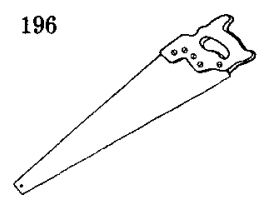

197

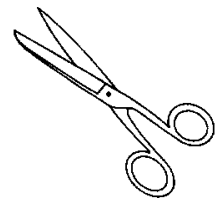

202

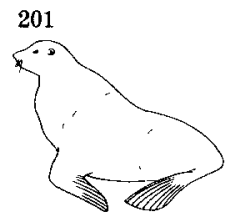

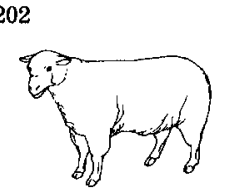

199

198
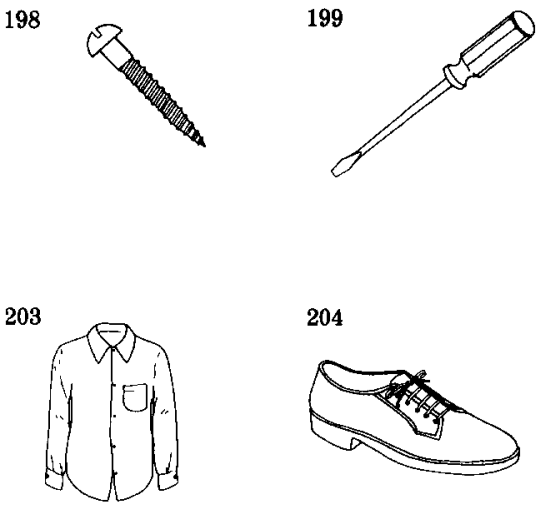

200

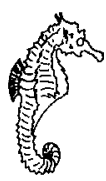

205

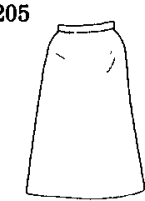



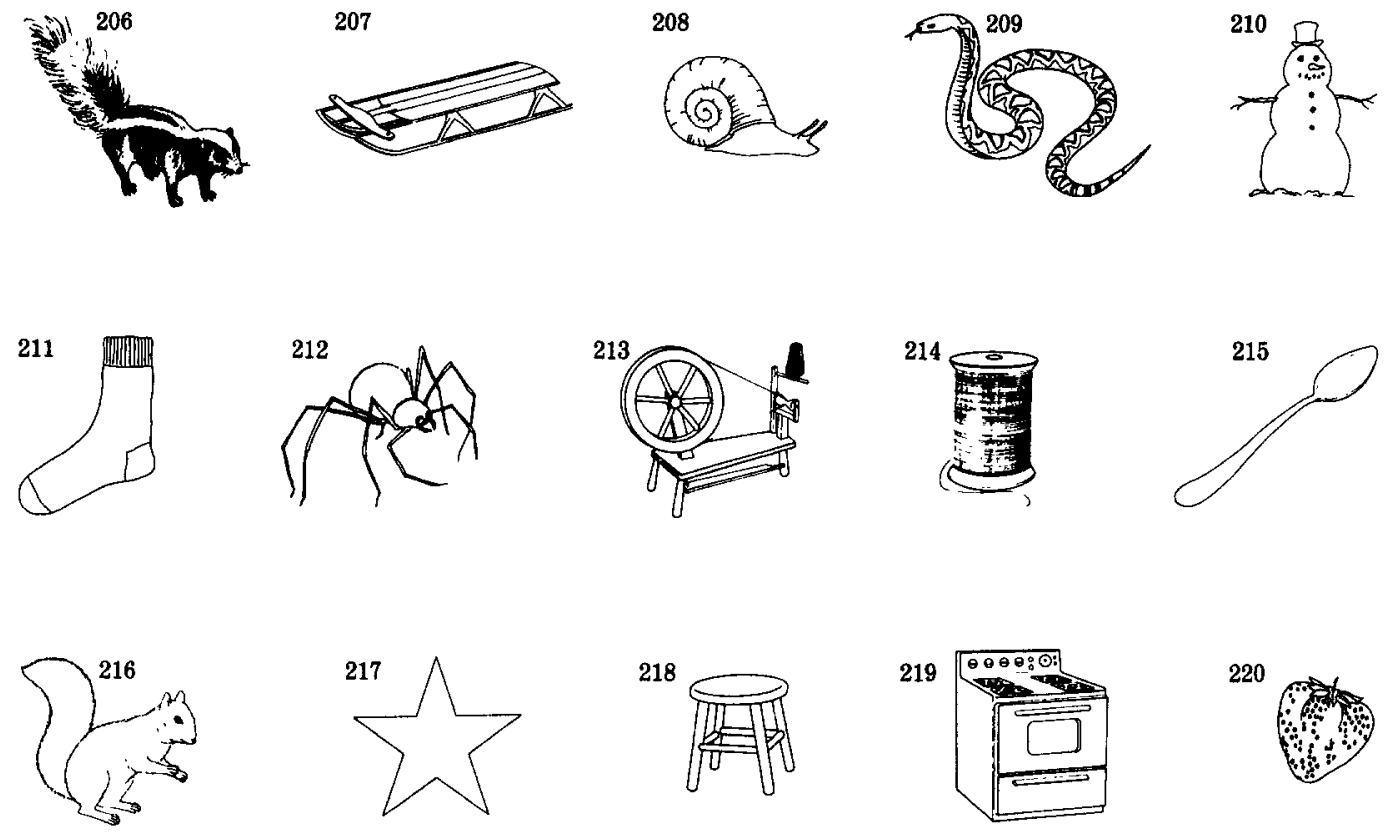

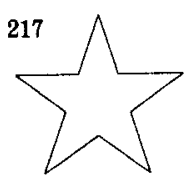

218

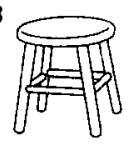

223
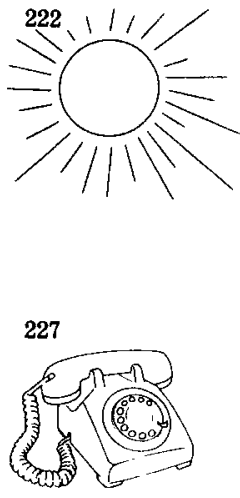
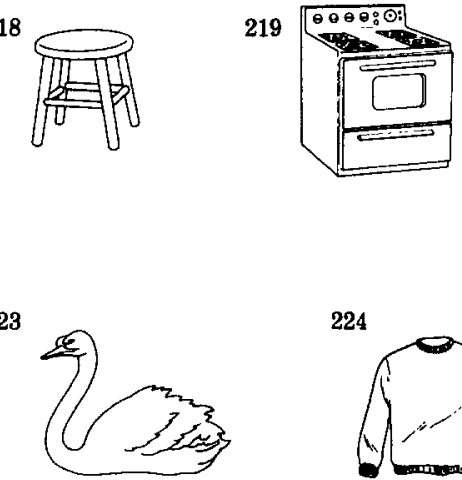

220
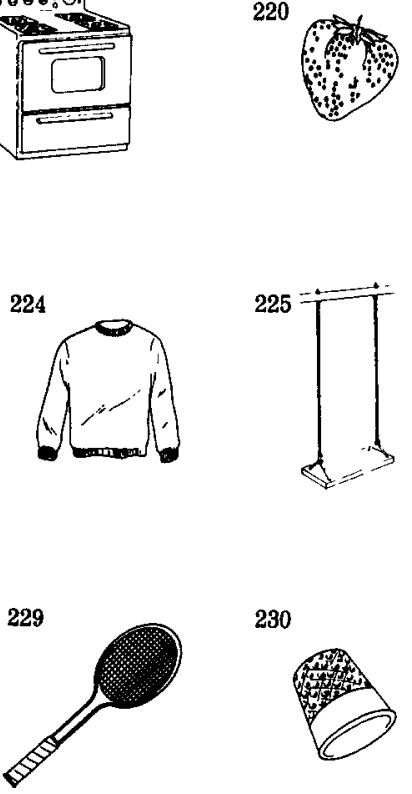

230

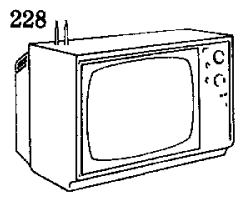

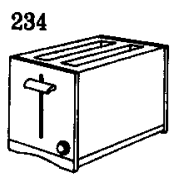
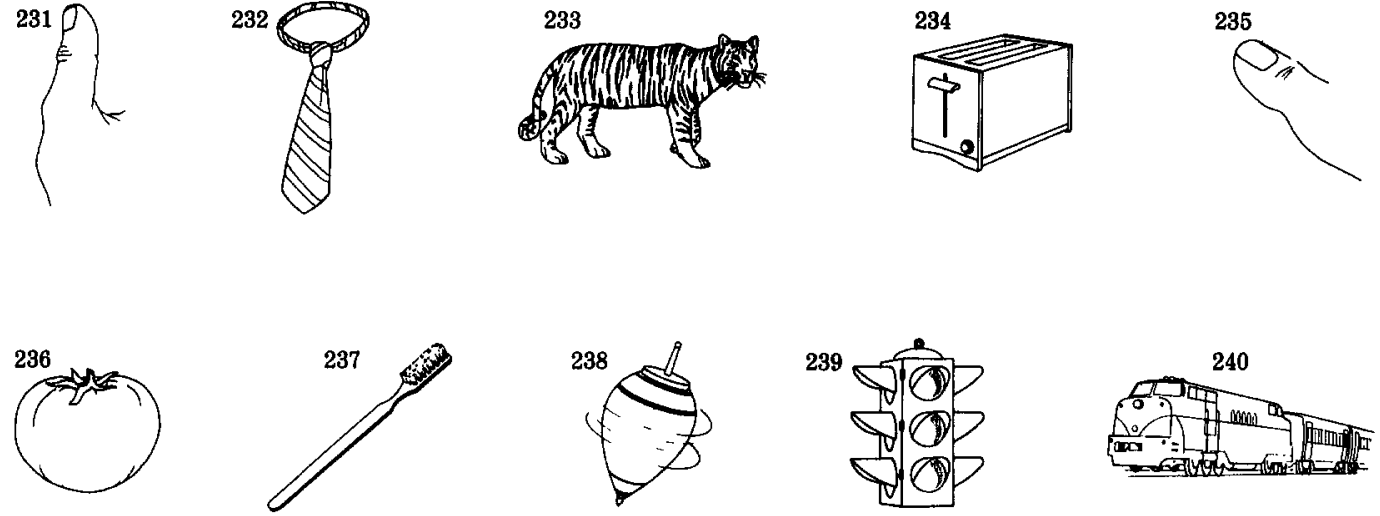

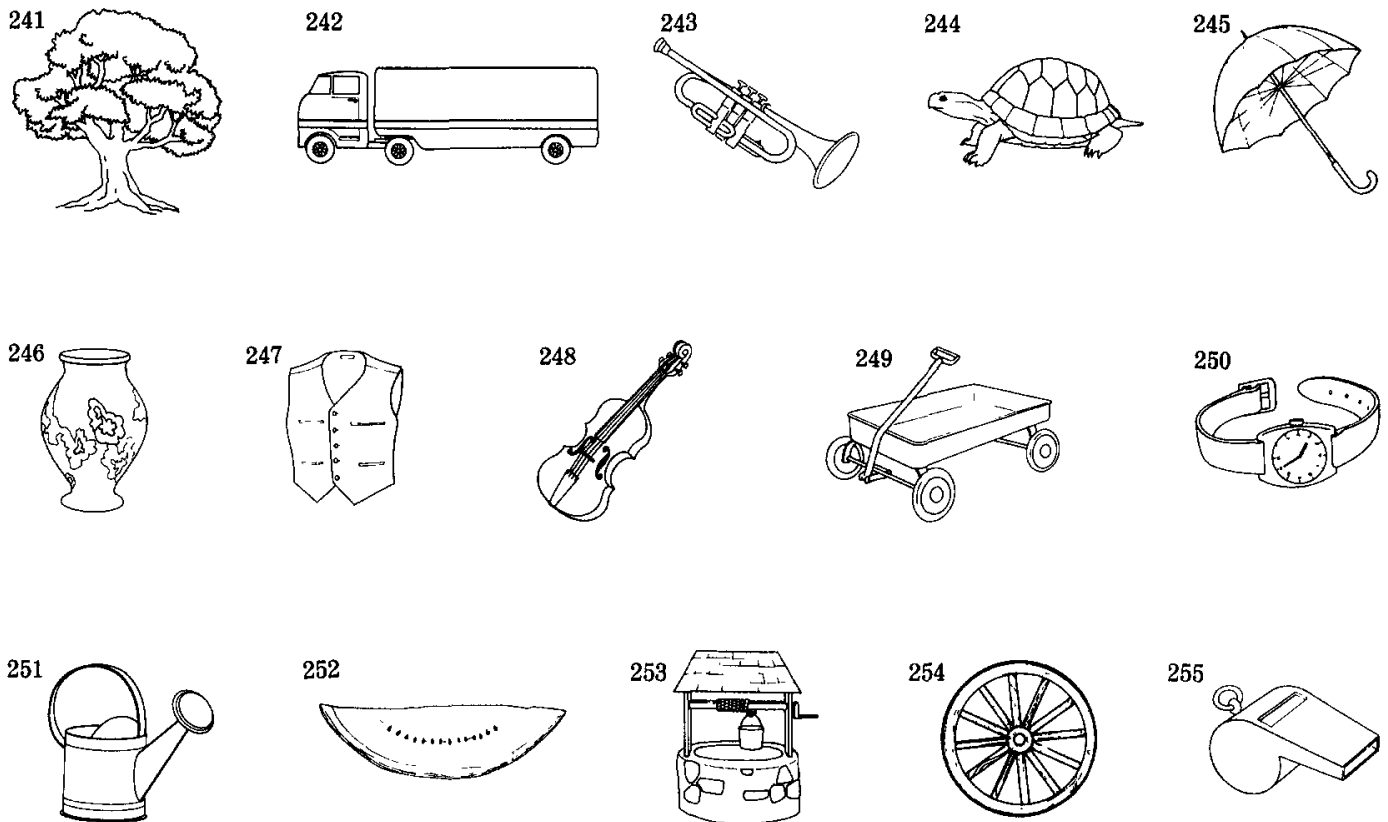

252
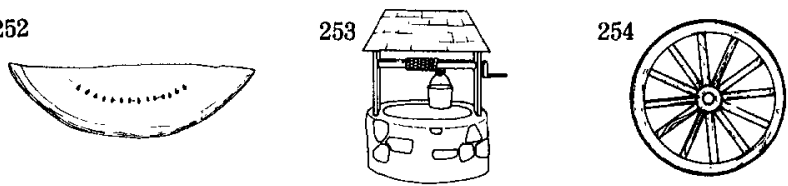

255

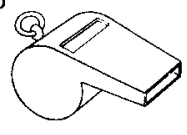

256
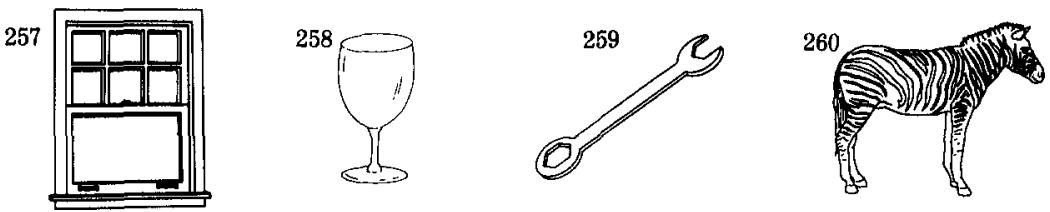
Appendix B

The following information is shown below: the identifying number of each picture; its most common name; two measures of name agreement, $H$ and percentage agreement; the mean and standard deviation for ratings of image agreement, familiarity and complexity; the KuceraFrancis frequency counts (K-F) for each single-word name; and the Carroll-White age-ofacquisition norms (A-A) for the 89 concepts for which they were available.

Table B1

Norms

\begin{tabular}{|c|c|c|c|c|c|c|c|c|c|c|}
\hline \multirow[b]{2}{*}{ Concept } & \multicolumn{2}{|c|}{ Name agree } & \multicolumn{2}{|c|}{ Image agree } & \multicolumn{2}{|c|}{ Familiarity } & \multicolumn{2}{|c|}{ Complexity } & \multirow[b]{2}{*}{$\mathrm{K}-\mathrm{F}$} & \multirow[b]{2}{*}{ A-A } \\
\hline & $H$ & $\%$ & $M$ & $S D$ & $M$ & $S D$ & $M$ & $S D$ & & \\
\hline 1. Accordion & .18 & 88 & 3.40 & 1.04 & 2.15 & 1.20 & 4.68 & .61 & 1 & 4.83 \\
\hline 2. Airplane & 1.77 & 60 & 3.23 & 1.12 & 3.78 & .99 & 3.50 & .10 & 11 & 2.59 \\
\hline 3. Alligator & .54 & 88 & 3.98 & .85 & 1.65 & .82 & 4.08 & .88 & 4 & 3.69 \\
\hline 4. Anchor & .17 & 93 & 4.32 & .85 & 1.60 & .83 & 2.58 & .70 & 15 & 4.88 \\
\hline 5. Ant & .64 & 81 & 2.92 & 1.24 & 2.62 & 1.11 & 3.92 & .82 & 6 & - \\
\hline 6. Apple & .16 & 98 & 4.05 & .87 & 3.98 & 1.08 & 1.82 & .67 & 9 & 1.91 \\
\hline 7. Arm & .53 & 90 & 3.95 & .89 & 4.75 & .58 & 2.15 & .61 & 94 & - \\
\hline 8. Arrow & .16 & 98 & 2.27 & 1.29 & 3.38 & 1.23 & 1.05 & .31 & 14 & 3.97 \\
\hline 9. Artichoke & 1.54 & 52 & 3.44 & 1.47 & 2.29 & 1.45 & 3.72 & .77 & 0 & - \\
\hline 10. Ashtray & .00 & 100 & 3.20 & 1.05 & 3.56 & 1.37 & 2.25 & .89 & 0 & - \\
\hline 11. Asparagus & 1.27 & 69 & 3.50 & 1.26 & 2.68 & 1.38 & 3.32 & .79 & 1 & - \\
\hline 12. Axe & .53 & 90 & 4.50 & .63 & 2.28 & 1.10 & 2.48 & .74 & 12 & 4.38 \\
\hline 13. Baby carriage & 1.00 & 52 & 3.65 & 1.01 & 2.72 & 1.14 & 3.42 & .10 & - & - \\
\hline 14. Ball & .44 & 93 & 2.84 & 1.19 & 3.20 & 1.21 & 2.28 & .81 & 110 & 1.34 \\
\hline 15. Balloon & .00 & 100 & 4.33 & 1.18 & 2.58 & 1.02 & 1.55 & .59 & 10 & 2.03 \\
\hline 16. Banana & .00 & 100 & 4.42 & .70 & 3.65 & 1.04 & 1.32 & .47 & 4 & 1.90 \\
\hline 17. Barn & 1.31 & 69 & 3.22 & 1.11 & 2.38 & 1.06 & 3.30 & .98 & 29 & - \\
\hline 18. Barrel & .00 & 100 & 4.31 & 1.14 & 2.02 & 1.13 & 3.32 & .93 & 24 & - \\
\hline 19. Baseball bat & 1.00 & 52 & 4.58 & .70 & 3.68 & 1.15 & 1.20 & .40 & 一 & - \\
\hline 20. Basket & .60 & 90 & 2.62 & 1.23 & 2.18 & .97 & 4.30 & .84 & 17 & 3.12 \\
\hline 21. Bear & .53 & 88 & 3.62 & 1.09 & 1.98 & 1.01 & 3.68 & .90 & 57 & 2.36 \\
\hline 22. Bed & .00 & 100 & 3.65 & .99 & 4.72 & .77 & 2.85 & .79 & 127 & - \\
\hline 23. Bee & 1.65 & 60 & 2.78 & 1.17 & 2.68 & 1.19 & 4.75 & .49 & 11 & 2.28 \\
\hline 24. Beetle & 2.18 & 50 & 2.05 & 1.13 & 1.88 & 1.00 & 3.65 & .82 & 0 & - \\
\hline 25. Bell & .00 & 100 & 2.92 & .94 & 2.20 & .93 & 2.62 & .66 & 18 & 2.36 \\
\hline 26. Belt & .16 & 98 & 4.05 & 1.01 & 4.12 & 1.05 & 2.00 & .59 & 29 & - \\
\hline 27. Bicycle & .53 & 88 & 3.40 & 1.09 & 3.78 & 1.04 & 3.85 & .11 & 5 & 2.45 \\
\hline 28. Bird & .69 & 88 & 3.33 & 1.14 & 3.62 & 1.16 & 3.25 & .73 & 31 & - \\
\hline 29. Blouse & 1.89 & 43 & 2.80 & 1.09 & 4.18 & .97 & 3.10 & .66 & 1 & 4.36 \\
\hline 30. Book & .00 & 100 & 4.33 & 1.00 & 4.75 & .54 & 2.10 & .66 & 193 & 1.83 \\
\hline 31. Boot & .69 & 88 & 2.28 & .96 & 3.38 & 1.24 & 2.45 & .70 & 13 & - \\
\hline 32. Bottle & .28 & 95 & 2.85 & 1.22 & 3.72 & 1.05 & 1.68 & .79 & 76 & - \\
\hline 33. Bow & 1.25 & 74 & 2.67 & 1.25 & 2.25 & 1.18 & 2.75 & .86 & 15 & - \\
\hline 34. Bowl & .17 & 95 & 3.79 & .89 & 4.18 & .92 & 1.82 & .80 & 23 & - \\
\hline 35. Box & .80 & 88 & 2.90 & 1.18 & 2.88 & 1.31 & 1.38 & .76 & 70 & - \\
\hline 36. Bread & .84 & 83 & 4.02 & 1.06 & 4.40 & .83 & 1.95 & .67 & 41 & - \\
\hline 37. Broom & .00 & 100 & 4.35 & .73 & 3.42 & 1.14 & 2.42 & .80 & 2 & 2.97 \\
\hline 38. Brush & .88 & 83 & 3.20 & 1.27 & 3.80 & 1.08 & 2.82 & .74 & 44 & - \\
\hline 39. Bus & .00 & 100 & 4.08 & 1.01 & 4.50 & .74 & 3.95 & .10 & 34 & 2.31 \\
\hline 40. Butterfly & .00 & 100 & 3.92 & .85 & 2.92 & 1.17 & 4.25 & .77 & 2 & 2.97 \\
\hline 41. Button & .16 & 98 & 4.48 & .92 & 3.85 & 1.26 & 2.02 & .76 & $10^{\circ}$ & - \\
\hline 42. Cake & .84 & 83 & 3.45 & 1.12 & 4.02 & 1.06 & 2.88 & .68 & 13 & 2.06 \\
\hline 43. Camel & .00 & 95 & 3.92 & .99 & 2.08 & 1.06 & 3.75 & .73 & 1 & - \\
\hline 44. Candle & .00 & 100 & 3.85 & .76 & 3.08 & 1.15 & 2.48 & .90 & 18 & 一 \\
\hline
\end{tabular}


Table B1 (continued)

\begin{tabular}{|c|c|c|c|c|c|c|c|c|c|c|}
\hline \multirow[b]{2}{*}{ Concept } & \multicolumn{2}{|c|}{ Name agree } & \multicolumn{2}{|c|}{ Image agree } & \multicolumn{2}{|c|}{ Familiarity } & \multicolumn{2}{|c|}{ Complexity } & \multirow[b]{2}{*}{$\mathrm{K}-\mathrm{F}$} & \multirow[b]{2}{*}{ A-A } \\
\hline & $H$ & $\%$ & $M$ & $S D$ & $M$ & $S D$ & $M$ & $S D$ & & \\
\hline 45. Cannon & .49 & 90 & 3.52 & .97 & 1.52 & .63 & 3.92 & .82 & 7 & - \\
\hline 46. Cap & .59 & 86 & 2.68 & 1.32 & 3.12 & 1.12 & 2.18 & .74 & 27 & - \\
\hline 47. Car & 1.08 & 81 & 3.10 & 1.22 & 4.70 & .60 & 4,05 & .95 & 274 & - \\
\hline 48. Carrot & .00 & 100 & 4.50 & .67 & 3.55 & .97 & 2.95 & .77 & 1 & - \\
\hline 49. Cat & .00 & 100 & 3.78 & .91 & 4.22 & .88 & 3.25 & .94 & 23 & 1.36 \\
\hline 50. Caterpillar & .96 & 79 & 2.38 & 1.23 & 1.72 & .81 & 3.58 & .10 & 1 & 3.90 \\
\hline 51. Celery & .83 & 76 & 3.75 & 1.14 & 3.40 & 1.11 & 4.25 & .86 & 4 & - \\
\hline 52. Chain & .16 & 98 & 4.46 & .84 & 2.82 & 1.00 & 2.55 & .97 & 50 & - \\
\hline 53. Chair & .00 & 100 & 3.22 & 1.28 & 4.58 & .86 & 2.05 & .70 & 66 & 1.86 \\
\hline 54. Cherry & .52 & 83 & 4.52 & .81 & 3.38 & 1.18 & 1.60 & .62 & 6 & - \\
\hline 55. Chicken & 1.35 & 67 & 3.62 & 1.28 & 2.42 & 1.09 & 3.48 & .90 & 37 & - \\
\hline 56. Chisel & 2.33 & 33 & 3.15 & 1.22 & 2.46 & 1.24 & 3.12 & .75 & 4 & - \\
\hline 57. Church & .44 & 93 & 2.98 & 1.31 & 3.38 & 1.34 & 3.28 & .11 & 348 & 2.62 \\
\hline 58. Cigar & .00 & 100 & 2.75 & .92 & 2.35 & 1.26 & 3.58 & .97 & 10 & 4.09 \\
\hline 59. Cigarette & .16 & 98 & 4.65 & .61 & 3.65 & 1.41 & 2.25 & .77 & 25 & 3.62 \\
\hline 60. Clock & .16 & 98 & 2.20 & .90 & 4.38 & .99 & 2.68 & .88 & 20 & 2.36 \\
\hline 61. Clothespin & .83 & 81 & 3.72 & 1.36 & 2.80 & 1.47 & 2.82 & .92 & 0 & 3.31 \\
\hline 62. Cloud & .17 & 95 & 2.85 & 1.30 & 3.82 & 1.19 & 2.12 & .87 & 28 & - \\
\hline 63. Clown & .28 & 95 & 3.25 & .89 & 2.60 & 1.16 & 4.50 & .81 & 3 & - \\
\hline 64. Coat & .95 & 79 & 2.59 & 1.32 & 3.88 & 1.19 & 2.55 & .67 & 43 & - \\
\hline 65. Comb & .44 & 93 & 3.78 & .85 & 4.52 & .87 & 2.38 & .83 & 6 & - \\
\hline 66. Corn & .88 & 81 & 4.08 & .85 & 3.50 & 1.05 & 3.58 & .86 & 34 & 2.94 \\
\hline 67. Couch & .92 & 67 & 3.05 & 1.05 & 4.40 & .74 & 2.28 & .84 & 12 & - \\
\hline 68. Cow & .44 & 93 & 3.92 & .90 & 2.42 & 1.20 & 3.85 & .96 & 29 & 1.90 \\
\hline 69. Crown & .00 & 100 & 2.85 & .79 & 1.52 & .81 & 4.25 & .77 & 19 & - \\
\hline 70. Cup & .44 & 93 & 3.65 & 1.35 & 4.40 & .83 & 1.78 & .52 & 45 & 1.66 \\
\hline 71. Deer & 1.44 & 76 & 3.72 & 1.05 & 2.22 & 1.21 & 3.55 & .77 & 13 & - \\
\hline 72. Desk & .32 & 95 & 3.18 & 1.39 & 4.32 & .90 & 3.05 & .84 & 65 & - \\
\hline 73. Dog & .00 & 100 & 3.05 & 1.26 & 4.60 & .70 & 3.38 & .73 & 75 & 1.55 \\
\hline 74. Doll & 1.42 & 71 & 2.28 & 1.07 & 2.92 & 1.14 & 4.12 & .93 & 10 & 1.55 \\
\hline 75. Donkey & .87 & 86 & 3.48 & 1.00 & 1.88 & .87 & 3.35 & .69 & 1 & - \\
\hline 76. Door & .16 & 98 & 3.80 & .87 & 4.68 & .79 & 3.22 & .69 & 312 & 1.97 \\
\hline 77. Doorknob & .38 & 90 & 3.90 & 1.00 & 4.25 & .92 & 2.68 & .61 & 3 & - \\
\hline 78. Dress & .00 & 100 & 2.30 & 1.08 & 3.62 & 1.46 & 2.65 & .65 & 67 & - \\
\hline 79. Dresser & 2.55 & 36 & 3.22 & .96 & 4.52 & .77 & 2.95 & .89 & 1 & - \\
\hline 80. Drum & .00 & 98 & 3.71 & 1.05 & 2.60 & 1.16 & 2.88 & .75 & 11 & 2.48 \\
\hline 81. Duck & .28 & 95 & 3.85 & .94 & 2.75 & 1.11 & 3.32 & .82 & 9 & - \\
\hline 82. Eagle & 1.14 & 76 & 3.49 & 1.26 & 2.42 & 1.30 & 4.18 & .74 & 5 & - \\
\hline 83. Ear & .28 & 95 & 4.26 & .93 & 4.50 & .70 & 2.68 & .82 & 29 & 1.82 \\
\hline 84. Elephant & .00 & 100 & 3.85 & .99 & 2,35 & 1.04 & 4.12 & .78 & 7 & 2.85 \\
\hline 85. Envelope & .16 & 98 & 4.70 & .64 & 4.12 & .93 & 1.42 & .59 & 21 & 3.93 \\
\hline 86. Eye & .16 & 98 & 4.15 & .88 & 4.88 & .40 & 3.48 & 1.10 & 122 & 2.00 \\
\hline 87. Fence & .94 & 74 & 3.80 & 1.44 & 3.02 & 1.06 & 2.55 & 1.00 & 30 & - \\
\hline 88. Finger & 1.37 & 71 & 4.60 & .66 & 4.78 & .79 & 2.30 & .95 & 40 & - \\
\hline 89. Fish & .00 & 100 & 3.58 & 1.05 & 3.28 & 1.22 & 3.75 & 1.02 & 35 & 2.61 \\
\hline 90. Flag & .32 & 95 & 3.22 & 1.19 & 2.90 & 1.28 & 1.88 & .46 & 16 & - \\
\hline 91. Flower & .48 & 93 & 3.25 & 1.01 & 3.88 & 1.19 & 3.25 & .94 & 23 & 2.15 \\
\hline 92. Flute & .61 & 88 & 3.41 & 1.30 & 2.45 & 1.22 & 4.15 & .85 & 1 & - \\
\hline 93. Fly & 1.15 & 76 & 3.22 & 1.33 & 3.02 & 1.06 & 4.10 & .92 & 33 & - \\
\hline 94. Foot & .28 & 95 & 4.42 & .86 & 4.78 & .69 & 2.18 & .89 & 70 & - \\
\hline 95. Football & .00 & 100 & 4.18 & .92 & 3.55 & 1.24 & 2.28 & .71 & 36 & - \\
\hline 96. Football he & .95 & 62 & 4.38 & .76 & 3.15 & 1.24 & 2.98 & .69 & - & - \\
\hline
\end{tabular}


Table B1 (continued)

\begin{tabular}{|c|c|c|c|c|c|c|c|c|c|c|}
\hline \multirow[b]{2}{*}{ Concept } & \multicolumn{2}{|c|}{ Name agree } & \multicolumn{2}{|c|}{ Image agree } & \multicolumn{2}{|c|}{ Familiarity } & \multicolumn{2}{|c|}{ Complexity } & \multirow[b]{2}{*}{ K-F } & \multirow[b]{2}{*}{$A-A$} \\
\hline & $H$ & $\%$ & $M$ & $S D$ & $M$ & $S D$ & $M$ & $S D$ & & \\
\hline 97. Fork & .00 & 100 & 4.15 & .85 & 4.78 & .47 & 2.62 & .94 & 14 & 2.24 \\
\hline 98. Fox & 1.27 & 74 & 3.49 & 1.20 & 1.95 & .84 & 4.02 & .85 & 13 & - \\
\hline 99. French horn & 1.67 & 57 & 3.73 & 1.36 & 2.00 & 1.05 & 4.30 & .87 & - & - \\
\hline 100. Frog & .00 & 100 & 3.60 & 1.02 & 2.48 & 1.05 & 3.42 & 1.05 & 1 & 3.15 \\
\hline 101. Frying pan & 1.18 & 60 & 3.92 & .93 & 4.15 & .96 & 2.05 & .67 & - & - \\
\hline 102. Garbage can & .76 & 88 & 4.52 & .74 & 4.08 & 1.10 & 2.58 & .74 & - & - \\
\hline 103. Giraffe & .32 & 95 & 4.48 & .81 & 1.80 & .95 & 4.65 & .73 & 0 & 4.07 \\
\hline 104. Glass & .16 & 98 & 4.40 & 1.00 & 4.78 & .52 & 1.82 & .74 & 99 & - \\
\hline 105. Glasses & 1.07 & 64 & 3.81 & .94 & 4.00 & 1.30 & 2.85 & .85 & 29 & - \\
\hline 106. Glove & .16 & 98 & 3.65 & 1.20 & 3.38 & 1.06 & 3.02 & .76 & 9 & 3.12 \\
\hline 107. Goat & .77 & 86 & 3.46 & 1.26 & 1.92 & 1.06 & 3.18 & .77 & 6 & - \\
\hline 108. Gorilla & .79 & 76 & 3.58 & 1.07 & 2.05 & 1.18 & 3.62 & .86 & 0 & - \\
\hline 109. Grapes & .38 & 90 & 4.31 & .79 & 3.65 & 1.04 & 3.00 & .92 & 7 & - \\
\hline 110. Grasshopper & 1.47 & 71 & 3.55 & 1.30 & 2.42 & 1.07 & 4.40 & .80 & 0 & - \\
\hline 111. Guitar & .16 & 98 & 4.20 & 1.21 & 3.58 & 1.09 & 4.00 & .92 & 19 & 5.41 \\
\hline 112. Gun & 1.09 & 74 & 3.82 & 1.05 & 2.68 & 1.19 & 3.52 & .81 & 118 & - \\
\hline 113. Hair & .64 & 90 & 2.71 & 1.18 & 4.59 & .74 & 2.88 & .78 & 148 & - \\
\hline 114. Hammer & .00 & 100 & 4.10 & 1.02 & 3.48 & 1.16 & 2.60 & .70 & 9 & 3.55 \\
\hline 115. Hand & .44 & 93 & 4.30 & .90 & 4.82 & .67 & 2.98 & .91 & 431 & - \\
\hline 116. Hanger & .74 & 86 & 4.73 & .55 & 4.52 & .67 & 1.20 & .56 & 0 & - \\
\hline 117. Harp & .00 & 93 & 4.28 & 1.06 & 1.88 & 1.08 & 4.05 & .81 & 1 & - \\
\hline 118. Hat & .16 & 98 & 3.65 & 1.22 & 3.18 & 1.00 & 2.35 & .79 & 56 & - \\
\hline 119. Heart & .00 & 100 & 4.49 & .98 & 3.72 & 1.16 & 1.00 & .00 & 173 & - \\
\hline 120. Helicopter & .32 & 95 & 3.42 & .97 & 2.55 & 1.12 & 3.80 & .95 & 1 & - \\
\hline 121. Horse & .00 & 100 & 4.20 & .81 & 3.55 & 1.14 & 3.82 & .70 & 117 & 2.67 \\
\hline 122. House & .32 & 95 & 2.65 & 1.11 & 4.38 & 1.04 & 3.90 & .94 & 591 & - \\
\hline 123. Iron & .32 & 95 & 4.08 & .76 & 3.65 & 1.08 & 3.25 & .89 & 43 & 3.88 \\
\hline 124. Ironing board & .56 & 83 & 4.40 & .77 & 3.50 & 1.07 & 2.05 & .63 & - & - \\
\hline 125. Jacket & .95 & 81 & 2.22 & .91 & 4.00 & 1.14 & 3.25 & .80 & 33 & - \\
\hline 126. Kangaroo & .00 & 100 & 4.30 & .75 & 1.92 & 1.15 & 3.98 & .88 & 0 & 4.55 \\
\hline 127. Kettle & 1.66 & 40 & 3.31 & 1.11 & 3.80 & 1.17 & 2.40 & .74 & 3 & - \\
\hline 128. Key & .00 & 100 & 4.58 & .74 & 4.85 & .42 & 1.92 & .76 & 88 & 3.38 \\
\hline 129. Kite & .00 & 100 & 4.10 & 1.00 & 2.48 & 1.14 & 2.85 & .69 & 1 & 3.72 \\
\hline 130. Knife & .60 & 90 & 3.25 & 1.32 & 4.45 & .84 & 1.92 & .68 & 76 & 2.70 \\
\hline 131. Ladder & .16 & 98 & 3.75 & 1.14 & 3.35 & 1.15 & 2.32 & .61 & 19 & 3.12 \\
\hline 132. Lamp & .44 & 93 & 3.26 & .90 & 4.20 & .95 & 1.85 & .61 & 18 & 2.72 \\
\hline 133. Leaf & .53 & 90 & 3.88 & 1.12 & 4.30 & .75 & 2.52 & .77 & 12 & 2.61 \\
\hline 134. Leg & 1.11 & 81 & 3.64 & 1.05 & 4.65 & .82 & 2.55 & .84 & 58 & - \\
\hline 135. Lemon & .00 & 100 & 4.35 & .94 & 3.25 & 1.22 & 1.85 & .69 & 18 & 3.06 \\
\hline 136. Leopard & 1.07 & 76 & 3.68 & 1.03 & 1.92 & .93 & 4.28 & .81 & 0 & 4.18 \\
\hline 137. Lettuce & 1.14 & 74 & 3.05 & 1.20 & 3.42 & 1.24 & 3.48 & .92 & 0 & - \\
\hline 138. Light bulb & .68 & 86 & 4.42 & .83 & 4.18 & .80 & 2.75 & .94 & - & - \\
\hline 139. Light switch & .92 & 67 & 4.62 & .62 & 4.58 & .63 & 2.52 & .77 & - & - \\
\hline 140. Lion & .37 & 93 & 3.88 & 1.03 & 2.00 & 1.07 & 4.30 & .87 & 17 & 2.82 \\
\hline 141. Lips & .44 & 93 & 4.10 & .94 & 4.50 & .81 & 1.85 & .88 & 69 & - \\
\hline 142. Lobster & .38 & 90 & 3.62 & 1.35 & 2.58 & 1.24 & 4.48 & .81 & 1 & 5.28 \\
\hline 143. Lock & .53 & 88 & 3.51 & 1.40 & 3.18 & 1.18 & 2.22 & .69 & 23 & - \\
\hline 144. Mitten & .96 & 76 & 3.82 & .96 & 3.10 & 1.22 & 2.35 & .69 & 0 & 3.06 \\
\hline 145. Monkey & .32 & 95 & 3.12 & 1.05 & 2.58 & .97 & 3.90 & .70 & 9 & - \\
\hline
\end{tabular}

(table continued) 
Table B1 (continued)

\begin{tabular}{|c|c|c|c|c|c|c|c|c|c|c|}
\hline \multirow[b]{2}{*}{ Concept } & \multicolumn{2}{|c|}{ Name agree } & \multicolumn{2}{|c|}{ Image agree } & \multicolumn{2}{|c|}{ Familiarity } & \multicolumn{2}{|c|}{ Complexity } & \multirow[b]{2}{*}{$\mathrm{K}-\mathrm{F}$} & \multirow[b]{2}{*}{ A-A } \\
\hline & $H$ & $\%$ & $M$ & $S D$ & $M$ & $S D$ & $M$ & $S D$ & & \\
\hline 146. Moon & 1.68 & 62 & 3.15 & 1.58 & 3.98 & 1.01 & 1.02 & .16 & 60 & - \\
\hline 147. Motorcycle & .32 & 95 & 3.64 & 1.05 & 3.25 & 1.09 & 4.78 & .47 & 0 & - \\
\hline 148. Mountain & .60 & 90 & 3.52 & 1.12 & 2.70 & 1.19 & 2.80 & 1.05 & 33 & 3.21 \\
\hline 149. Mouse & .75 & 79 & 4.22 & .91 & 2.45 & 1.02 & 3.28 & .87 & 10 & - \\
\hline 150. Mushroom & .00 & 98 & 3.78 & 1.11 & 2.88 & 1.23 & 3.12 & .71 & 2 & - \\
\hline 151. Nail & .16 & 98 & 4.73 & .62 & 3.28 & 1.20 & 1.80 & .68 & 6 & 3.58 \\
\hline 152. Nail file & 1.04 & 67 & 3.56 & 1.26 & 3.15 & 1.39 & 3.18 & 1,00 & - & - \\
\hline 153. Necklace & 1.88 & 60 & 3.32 & 1.49 & 2.70 & 1.31 & 1.78 & .88 & 3 & - \\
\hline 154. Needle & .86 & 81 & 4.42 & 1.14 & 3.40 & 1.14 & 1.55 & .74 & 15 & - \\
\hline 155. Nose & .16 & 98 & 3.62 & 1.18 & 4.52 & .87 & 1.60 & .92 & 60 & - \\
\hline 156. Nut & .97 & 64 & 3.62 & 1.65 & 2.55 & 1.28 & 2.30 & .56 & 15 & - \\
\hline 157. Onion & .00 & 95 & 3.90 & .80 & 3.32 & 1.31 & 2.85 & .96 & 15 & - \\
\hline 158. Orange & .53 & 81 & 4.00 & 1.07 & 3.34 & 1.26 & 2.12 & .71 & 23 & - \\
\hline 159. Ostrich & .35 & 86 & 3.32 & 1.03 & 1.52 & .67 & 3.70 & .81 & 0 & - \\
\hline 160. Owl & .00 & 100 & 4.10 & .92 & 2.22 & 1.06 & 4.22 & .72 & 2 & - \\
\hline 161. Paintbrush & 1.06 & 74 & 2.92 & 1.59 & 2.78 & 1.24 & 2.58 & .95 & 1 & - \\
\hline 162. Pants & .53 & 88 & 3.60 & .92 & 4.55 & .86 & 2.22 & .70 & 9 & - \\
\hline 163. Peach & 1.19 & 74 & 3.28 & 1.28 & 2.90 & 1.02 & 2.55 & .81 & 3 & 2.79 \\
\hline 164. Peacock & .81 & 79 & 3.64 & .97 & 2.05 & 1.05 & 4.75 & .43 & 2 & 5.18 \\
\hline 165. Peanut & .37 & 93 & 4.30 & .98 & 3.00 & 1.02 & 2.82 & .95 & 6 & - \\
\hline 166. Pear & .00 & 100 & 4.62 & .62 & 3.55 & 1.14 & 1.15 & .36 & 6 & - \\
\hline 167. Pen & .32 & 95 & 3.22 & 1.04 & 4.78 & .72 & 3.15 & .94 & 18 & - \\
\hline 168. Pencil & .00 & 100 & 4.40 & .80 & 4.42 & 1.00 & 2.32 & .91 & 34 & - \\
\hline 169. Penguin & .38 & 90 & 3.22 & 1.15 & 1.70 & .93 & 2.82 & .70 & 0 & 5.12 \\
\hline 170. Pepper & 1.07 & 67 & 3.64 & 1.28 & 2.92 & 1.29 & 2.48 & .95 & 13 & - \\
\hline 171. Piano & .70 & 81 & 4.02 & 1.06 & 3.42 & 1.48 & 4.58 & .77 & 38 & - \\
\hline 172. Pig & .60 & 90 & 3.62 & 1.04 & 2.18 & .97 & 3.00 & .81 & 8 & 2.94 \\
\hline 173. Pineapple & .00 & 100 & 4.60 & .62 & 2.95 & 1.30 & 4.35 & 1.01 & 9 & - \\
\hline 174. Pipe & .16 & 98 & 4.26 & 1.00 & 2.90 & 1.14 & 1.88 & .71 & 20 & 4.07 \\
\hline 175. Pitcher & .54 & 88 & 3.62 & .84 & 3.50 & .92 & 1.85 & .57 & 21 & 4.07 \\
\hline 176. Pliers & .38 & 88 & 4.22 & 1.15 & 3.38 & 1.13 & 2.20 & .60 & 1 & - \\
\hline 177. Plug & .29 & 88 & 4.08 & 1.02 & 4.18 & .77 & 2.25 & .70 & 23 & - \\
\hline 178. Pocketbook & 1.72 & .57 & 3.05 & .92 & 3.95 & 1.28 & 2.70 & .78 & 3 & - \\
\hline 179. Pot & .86 & 81 & 3.56 & .98 & 4.22 & .96 & 2.22 & .69 & 28 & - \\
\hline 180. Potato & .34 & 90 & 3.97 & 1.14 & 3.46 & 1.17 & 2.20 & 1.10 & 15 & 2.67 \\
\hline 181. Pumpkin & .00 & 98 & 4.18 & 1.18 & 3.08 & 1.35 & 2.60 & .70 & 2 & 3.69 \\
\hline 182. Rabbit & .00 & 100 & 4.20 & .81 & 2.95 & 1.07 & 3.28 & .84 & 11 & 2.61 \\
\hline 183. Raccoon & .58 & 79 & 3.08 & 1.08 & 2.20 & 1.23 & 4.40 & .83 & 1 & - \\
\hline 184. Record player & 1.73 & 50 & 3.35 & 1.22 & 4.40 & .86 & 3.32 & .93 & - & - \\
\hline 185. Refrigerator & .44 & 93 & 3.85 & 1.13 & 4.68 & .65 & 2.20 & .60 & 23 & - \\
\hline 186. Rhinoceros & .56 & 83 & 3.84 & .93 & 1.52 & .89 & 4.15 & .85 & 3 & \\
\hline 187. Ring & .16 & 98 & 3.08 & .96 & 3.48 & 1.28 & 2.55 & .80 & 47 & - \\
\hline 188. Rocking chair & .53 & 90 & 4.12 & .95 & 3.25 & 1.30 & 3.58 & .92 & - & - \\
\hline 189. Roller skate & 1.00 & 52 & 3.48 & 1.36 & 2.25 & 1.11 & 4.08 & .93 & - & - \\
\hline 190. Rolling pin & .94 & 71 & 4.44 & .96 & 2.22 & 1.08 & 1.52 & .50 & - & - \\
\hline 191. Rooster & 1.21 & 76 & 4.08 & .90 & 2.22 & 1.08 & 4.12 & .90 & 3 & - \\
\hline 192. Ruler & .16 & 98 & 3.98 & 1.04 & 3.58 & .95 & 1.85 & .94 & 3 & - \\
\hline 193. Sailboat & .37 & 93 & 3.25 & .99 & 2.92 & 1.17 & 3.58 & .92 & 1 & - \\
\hline 194. Saltshaker & .96 & 83 & 4.00 & 1.12 & 4.18 & .92 & 3.00 & .92 & 0 & - \\
\hline 195. Sandwich & .00 & 100 & 3.55 & .97 & 4.45 & .97 & 3.42 & .86 & 10 & - \\
\hline 196. Saw & .16 & 98 & 4.55 & .77 & 2.92 & 1.19 & 2.25 & .62 & 352 & - \\
\hline 197. Scissors & .16 & 98 & 4.40 & .83 & 3.98 & .99 & 2.15 & .65 & 1 & - \\
\hline
\end{tabular}


Table B1 (continued)

\begin{tabular}{|c|c|c|c|c|c|c|c|c|c|c|}
\hline \multirow[b]{2}{*}{ Concept } & \multicolumn{2}{|c|}{ Name agree } & \multicolumn{2}{|c|}{ Image agree } & \multicolumn{2}{|c|}{ Familiarity } & \multicolumn{2}{|c|}{ Complexity } & \multirow[b]{2}{*}{$K-F$} & \multirow[b]{2}{*}{ A-A } \\
\hline & $H$ & $\%$ & $M$ & $S D$ & $M$ & $S D$ & $M$ & $S D$ & & \\
\hline 198. Screw & .33 & 93 & 3.67 & .89 & 3.20 & 1.00 & 3.25 & .99 & 21 & 4.45 \\
\hline 199. Screwdriver & .00 & 98 & 4.30 & .64 & 3.42 & 1.14 & 2.35 & .73 & 0 & - \\
\hline 200. Sea horse & .34 & 88 & 3.58 & 1.22 & 1.50 & .89 & 4.50 & .71 & - & - \\
\hline 201. Seal & .61 & 88 & 3.18 & 1.06 & 1.62 & .73 & 2.90 & .74 & 17 & - \\
\hline 202. Sheep & .95 & 67 & 3.00 & 1.11 & 1.85 & .82 & 3.80 & .75 & 23 & - \\
\hline 203. Shirt & .00 & 100 & 3.86 & .98 & 4.56 & .70 & 3.08 & .79 & 27 & - \\
\hline 204. Shoe & .28 & 95 & 3.02 & 1.26 & 4.62 & .70 & 3.38 & .86 & 14 & 1.94 \\
\hline 205. Skirt & .16 & 98 & 3.28 & 1.10 & 3.64 & 1.53 & 1.40 & .58 & 21 & - \\
\hline 206. Skunk & .16 & 98 & 3.40 & 1.09 & 2.30 & 1.17 & 4.72 & .74 & 0 & - \\
\hline 207. Sled & .00 & 98 & 4.49 & .81 & 2.80 & 1.03 & 3.05 & .84 & 0 & - \\
\hline 208. Snail & .51 & 86 & 3.33 & 1.18 & 1.85 & 1.06 & 3.40 & .80 & 1 & 5.10 \\
\hline 209. Snake & .16 & 98 & 3.54 & 1.01 & 1.90 & 1.04 & 4.52 & .81 & 44 & 3.52 \\
\hline 210. Snowman & .00 & 100 & 4.00 & .95 & 3.15 & 1.04 & 2.52 & .59 & 0 & - \\
\hline 211. Sock & .00 & 100 & 3.72 & 1.00 & 4.52 & .84 & 1.62 & .62 & 4 & - \\
\hline 212. Spider & .61 & 88 & 2.95 & 1.16 & 2.28 & 1.10 & 3.68 & .85 & 2 & - \\
\hline 213. Spinning wheel & 2.04 & 50 & 3.10 & 1.32 & 1.18 & .54 & 4.25 & .92 & - & - \\
\hline 214. Spool of thread & 1.54 & 55 & 3.80 & 1.44 & 3.12 & 1.14 & 3.18 & .97 & - & - \\
\hline 215. Spoon & .16 & 98 & 4.10 & 1.11 & 4.50 & .89 & 2.02 & .82 & 6 & 1.97 \\
\hline 216. Squirrel & .17 & 93 & 4.42 & .89 & 3.82 & .89 & 3.75 & .97 & 1 & - \\
\hline 217. Star & .00 & 100 & 4.41 & 1.10 & 3.35 & 1.33 & 1.05 & .22 & 25 & - \\
\hline 218. Stool & .16 & 98 & 4.12 & 1.08 & 3.08 & 1.13 & 2.32 & .72 & 8 & - \\
\hline 219. Stove & 1.12 & 76 & 4.10 & 1.00 & 4.65 & .65 & 4.02 & .94 & 15 & 2.72 \\
\hline 220. Strawberry & .17 & 90 & 3.98 & 1.04 & 3.20 & 1.29 & 3.38 & .91 & 0 & 3.61 \\
\hline 221. Suitcase & 1.01 & 79 & 2.98 & 1.17 & 3.65 & .91 & 3.60 & .86 & 20 & - \\
\hline 222. Sun & .00 & 100 & 4.22 & 1.08 & 4.90 & .30 & 1.20 & .46 & 112 & - \\
\hline 223. Swan & .64 & 88 & 3.69 & .72 & 1.97 & .83 & 3.05 & .80 & 3 & - \\
\hline 224. Sweater & .98 & 83 & 2.78 & 1.11 & 4.48 & .74 & 2.90 & .77 & 14 & - \\
\hline 225. Swing & .17 & 95 & 4.15 & .92 & 3.02 & 1.24 & 2.72 & .97 & 24 & - \\
\hline 226. Table & .32 & 95 & 3.42 & 1.36 & 4.35 & .88 & 1.72 & .77 & 198 & 2.45 \\
\hline 227. Telephone & .59 & 86 & 4.28 & 1.16 & 4.80 & .51 & 3.52 & .97 & 76 & - \\
\hline 228. Television & 1.46 & 52 & 4.00 & .82 & 4.82 & .38 & 3.22 & .96 & 50 & 2.62 \\
\hline 229. Tennis racket & .62 & 86 & 4.62 & .58 & 3.62 & 1.30 & 3.25 & .94 & - & - \\
\hline 230. Thimble & .63 & 83 & 4.26 & .93 & 2.48 & 1.12 & 3.35 & .82 & 1 & - \\
\hline 231. Thumb & .16 & $\begin{array}{l}00 \\
98\end{array}$ & 4.48 & .63 & 4.72 & .74 & 2.38 & .97 & 10 & - \\
\hline 232. Tie & .80 & 69 & $\begin{array}{l}4.40 \\
4.05\end{array}$ & .00 & 3.80 & 1.03 & 2.90 & .80 & 23 & - \\
\hline 233. Tiger & .09 & 93 & 3.82 & 1.14 & 2.10 & $\begin{array}{r}1.00 \\
.92\end{array}$ & 4.62 & .80 & 7 & - \\
\hline 234. Toaster & .00 & 100 & 3.92 & $\begin{array}{r}1.17 \\
.79\end{array}$ & 4.08 & .90 & 2.78 & .85 & 0 & - \\
\hline 235. Toe & 1.57 & 55 & 4.18 & .83 & 4.48 & .81 & 1.98 & .82 & 9 & - \\
\hline 236. Tomato & .80 & 88 & 4.05 & 1.12 & 3.78 & 1.06 & 1.98 & .57 & 4 & - \\
\hline 237. Toothbrush & .16 & 98 & 4.40 & .74 & 4.62 & .73 & 2.42 & .77 & 6 & - \\
\hline 238. Top & .68 & 86 & 3.46 & 1.05 & 1.88 & .98 & 2.65 & .82 & 204 & - \\
\hline 239. Traffic light & 1.40 & 67 & 4.08 & .98 & $\begin{array}{l}1.00 \\
4.55\end{array}$ & .80 & 3.45 & .84 & - & - \\
\hline 240. Train & $\begin{array}{r}.74 \\
.74\end{array}$ & 86 & 3.20 & 1.38 & 4.15 & .88 & 4.32 & .88 & 82 & - \\
\hline 241. Tree & .00 & 100 & 3.52 & 1.00 & 4.68 & .61 & 3.70 & .81 & 59 & 2.03 \\
\hline 242. Truck & .53 & 90 & 2.80 & 1.10 & 4.02 & .91 & 2.75 & .86 & 57 & - \\
\hline 243. Trumpet & 1.10 & 79 & 2.89 & 1.42 & 2.60 & 1.26 & 3.58 & .92 & 7 & - \\
\hline 244. Turtle & .32 & 95 & 4.12 & .95 & 2.40 & 1.14 & 3.62 & .89 & 8 & 2.97 \\
\hline 245. Umbrella & .00 & 100 & 3.92 & .90 & 3.95 & .92 & 3.00 & 1.05 & 8 & 4.09 \\
\hline 246. Vase & .32 & 95 & 2.72 & 1.02 & 2.78 & 1.26 & 3.15 & .66 & 4 & 4.30 \\
\hline 247. Vest & .16 & 98 & 3.70 & 1.10 & 3.48 & 1.05 & 2.60 & .74 & 4 & - \\
\hline 248. Violin & .72 & 86 & 4.18 & 1.05 & 2.68 & 1.21 & 4.10 & .86 & 11 & - \\
\hline 249. Wagon & .92 & 79 & 3.56 & 1.63 & 2.50 & 1.22 & 3.35 & .91 & 55 & 3.03 \\
\hline 250. Watch & .45 & 90 & 3.18 & 1.07 & 4.58 & .73 & 3.40 & 1.04 & 81 & - \\
\hline
\end{tabular}


Table B1 (continued)

\begin{tabular}{|c|c|c|c|c|c|c|c|c|c|c|}
\hline \multirow[b]{2}{*}{ Concept } & \multicolumn{2}{|c|}{ Name agree } & \multicolumn{2}{|c|}{ Image agree } & \multicolumn{2}{|c|}{ Familiarity } & \multicolumn{2}{|c|}{ Complexity } & \multirow[b]{2}{*}{$\mathrm{K}-\mathrm{F}$} & \multirow[b]{2}{*}{ A-A } \\
\hline & $H$ & $\%$ & $M$ & $S D$ & $M$ & $S D$ & $M$ & $S D$ & & \\
\hline 251. Watering can & 2.03 & 55 & 4.08 & .98 & 2.72 & 1.50 & 2.78 & .79 & - & - \\
\hline 252. Watermelon & .55 & 86 & 2.85 & 1.31 & 3.05 & 1.09 & 2.28 & .92 & 1 & - \\
\hline 253. Well & .60 & 90 & 4.18 & .86 & 1.45 & .70 & 3.82 & .74 & 897 & - \\
\hline 254. Wheel & .33 & 93 & 3.48 & 1.36 & 2.22 & 1.04 & 2.42 & .83 & 56 & - \\
\hline 255. Whistle & .00 & 100 & 4.55 & .67 & 2.45 & .92 & 2.55 & .84 & 4 & - \\
\hline 256. Windmill & .16 & 98 & 3,35 & 1.08 & 1.80 & 1.00 & 4.62 & .76 & 1 & 5.48 \\
\hline 257. Window & .32 & 95 & 3.25 & .83 & 4.40 & .86 & 3.18 & .86 & 119 & 2.28 \\
\hline 258. Wineglass & 1.43 & 50 & 3.31 & 1.35 & 4.02 & 1.11 & 1.85 & .48 & 0 & - \\
\hline 259. Wrench & .89 & 76 & 2.51 & 1.18 & 2.72 & 1.28 & 2.02 & .79 & 0 & - \\
\hline 260. Zebra & .00 & 98 & 4.05 & .74 & 1.60 & .83 & 4.55 & .70 & 1 & - \\
\hline
\end{tabular}

\section{Appendix C}

Shown here are all the concepts for which one or more naming, imaging, or identification failure occurred, a different object was imaged, or more than one name was given. Failures in the naming task are listed as DKO (don't know object), DKN (don't know name) and TOT (tip of the tongue). Identification failures in the familiarity rating task are listed as DKO (FAM). Imaging failures in the image agreement task are listed as NI (no image) and imaging a different object as DO (different object). All nondominant names given for each concept are listed accompanied by their frequencies. For names given by a single subject, only the name is listed without the frequency.

Table C1

Norms

\begin{tabular}{|c|c|c|c|c|c|c|c|}
\hline Concept & DKO & DKN & TOT & $\begin{array}{l}\text { DKO } \\
\text { (FAM) }\end{array}$ & NI & DO & Nondominant names \\
\hline 1. Accordion & $\mathbf{0}$ & 1 & 3 & 0 & 0 & 0 & Organ \\
\hline 2. Airplane & 0 & 0 & 0 & 0 & 1 & 0 & $\begin{array}{l}\text { Plane } 8 \text {, jet } 4 \text {, jet plane } 2 \text {, } \\
\text { jet airplane } 2 \text {, airplane- } 747\end{array}$ \\
\hline 3. Alligator & 0 & 0 & 1 & 0 & 0 & 0 & Crocodile 3, lizard \\
\hline 4. Anchor & 0 & 2 & 0 & 0 & 0 & 0 & Ship's anchor \\
\hline 5. Ant & 1 & 3 & 0 & 0 & 1 & 1 & Insect 2 , spider, bug \\
\hline 6. Apple & 0 & 0 & $\mathbf{0}$ & 0 & 0 & 0 & Fruit \\
\hline 7. Arm & 0 & 0 & 0 & 0 & 0 & 0 & Left $\operatorname{arm} 3$, hand \\
\hline 8. Arrow & 0 & 0 & 0 & 1 & 0 & 7 & One-way sign \\
\hline 9. Artichoke & 3 & 6 & 3 & 5 & 15 & 1 & $\begin{array}{l}\text { Avocado 4, pineapple, bud, brussel, } \\
\text { sprout, squash }\end{array}$ \\
\hline 10. Ashtray & $\mathbf{0}$ & 0 & 0 & 1 & 0 & 0 & - \\
\hline 11. Asparagus & 1 & 3 & 1 & 2 & 3 & 1 & $\begin{array}{l}\text { Asparagus spear } 3 \text {, branch of willows, } \\
\text { twig, pine tree, cauliflower, branch }\end{array}$ \\
\hline 12. Axe & $\mathbf{0}$ & 0 & 0 & 0 & 0 & 0 & Hatchet 3 , hammer \\
\hline 13. Baby carriage & 0 & 0 & 1 & 0 & 0 & 0 & Carriage 19 \\
\hline 14. Ball & 0 & 0 & 0 & 0 & 1 & 0 & Beach ball 2 , top \\
\hline 15. Balloon & 0 & 0 & 0 & 0 & 0 & 1 & - \\
\hline 17. Barn & 0 & 0 & 0 & 0 & 0 & 0 & $\begin{array}{l}\text { Barn and silo } 9, \text { farm 2, barn house, } \\
\text { farmhouse }\end{array}$ \\
\hline
\end{tabular}

(table continued) 


\begin{tabular}{|c|c|c|c|c|c|c|c|}
\hline Concept & $\mathrm{DKO}$ & $\mathrm{DKN}$ & TOT & $\begin{array}{c}\text { DKO } \\
\text { (FAM) }\end{array}$ & NI & DO & Nondominant names \\
\hline 18. Barrel & 0 & 0 & 0 & 0 & 0 & 1 & 一 \\
\hline 19. Baseball bat & 0 & 0 & 0 & 0 & 0 & 0 & Bat 20 \\
\hline 20. Basket & 0 & 0 & 0 & 0 & 0 & 1 & $\begin{array}{l}\text { Picnic basket } 2 \text {, lunch basket, } \\
\text { wicker basket }\end{array}$ \\
\hline 21. Bear & 0 & 0 & 0 & 0 & 0 & 0 & Polar bear 5 \\
\hline 23. Bee & 0 & 2 & 0 & 0 & 0 & 0 & $\begin{array}{l}\text { Fly } 8 \text {, insect } 3 \text {, bug } 2 \text {, bumble bee, } \\
\text { mosquito }\end{array}$ \\
\hline 24. Beetle & 0 & 2 & 1 & 0 & 1 & 0 & $\begin{array}{l}\text { Insect } 4 \text {, bug } 4 \text {, cockroach } 4 \text {, roach } 3 \text {, } \\
\text { cricket, ant, dico }\end{array}$ \\
\hline 25. Bell & 0 & 0 & 0 & 0 & 0 & 1 & - \\
\hline 26. Belt & 0 & 0 & 0 & 0 & 0 & 1 & Collar \\
\hline 27. Bicycle & 0 & 0 & 0 & 0 & 0 & 0 & Bike 5 \\
\hline 28. Bird & 0 & 0 & 0 & 0 & 1 & 0 & Sparrow 3, chickadee, baby chick \\
\hline 29. Blouse & 0 & 0 & 0 & 0 & 1 & 0 & $\begin{array}{l}\text { Shirt } 16 \text {, jacket } 4 \text {, sweater, coat, } \\
\text { ladies jacket, stylish shirt }\end{array}$ \\
\hline 30. Book & 0 & 0 & 0 & 0 & 1 & 0 & - \\
\hline 31. Boot & 0 & 0 & 0 & 0 & 0 & 1 & Shoe 3 , rubber boot, half-boot \\
\hline 32. Bottle & 0 & 0 & 0 & 0 & 0 & 0 & Wine bottle 2 \\
\hline 33. Bow & 0 & 0 & 0 & 0 & 0 & 13 & Ribbon 6 , bowtie 3 , tie, ribbon bow \\
\hline 34. Bowl & 0 & 0 & 1 & 0 & 0 & 2 & Dish \\
\hline 35. Box & 0 & 0 & 0 & 0 & 0 & 0 & $\begin{array}{l}\text { Cube, shoe box, index card box, } \\
\text { cardboard box, index file box }\end{array}$ \\
\hline 36. Bread & 0 & 0 & 0 & 0 & 0 & 0 & $\begin{array}{l}\text { Loaf of bread } 5 \text {, slice of bread, } \\
\text { loaf of bread and slice }\end{array}$ \\
\hline 38. Brush & $\mathbf{0}$ & 0 & 0 & 0 & 0 & 0 & $\begin{array}{l}\text { Hair brush } 4 \text {, shoe brush } 2 \text {, lint } \\
\text { brush }\end{array}$ \\
\hline 41. Button & 0 & 0 & 0 & 0 & 0 & 0 & Wheel \\
\hline 42. Cake & 0 & 0 & 0 & 0 & 0 & 0 & $\begin{array}{l}\text { Layer cake } 5 \text {, piece of cake, } \\
\text { three-layer cake }\end{array}$ \\
\hline 43. Camel & 0 & 0 & 2 & 0 & 0 & 0 & - \\
\hline 45. Cannon & 0 & 1 & 0 & 0 & 0 & 0 & War gun, gun, cannon (civil war) \\
\hline 46. Cap & 0 & 0 & 0 & 0 & 1 & 2 & Hat 6 \\
\hline 47. Car & 0 & 0 & 0 & 0 & 0 & 0 & $\begin{array}{l}\text { Lincoln } 4 \text {, automobile, motor car, } \\
\text { luxury car, luxury automobile }\end{array}$ \\
\hline 50. Caterpillar & 1 & 1 & 0 & 0 & 0 & 1 & Centipede 4 , snail, worm, inchworm \\
\hline 51. Celery & 0 & 3 & 1 & 0 & 0 & 0 & Lettuce 4 , staff of celery, celery stalk \\
\hline 52. Chain & 0 & 0 & 0 & 0 & 0 & 1 & Chain links \\
\hline 54. Cherry & 1 & 2 & 1 & 0 & 0 & 0 & Peach, grape, plum \\
\hline 55. Chicken & 0 & 0 & 0 & 0 & 0 & 0 & Hen 10 , turkey 2 , rooster, bird \\
\hline 56. Chisel & 4 & 5 & 2 & 1 & 5 & 1 & $\begin{array}{l}\text { Screwdriver } 8 \text {, tool } 2 \text {, scraper } 2 \\
\text { wedge, awl, wood chisel, file, } \\
\text { knife }\end{array}$ \\
\hline 57. Church & 0 & 0 & 0 & 0 & 0 & 0 & Chapel 2, church house \\
\hline 59. Cigarette & 0 & $\mathbf{0}$ & 0 & 0 & 0 & 0 & Burning cigarette \\
\hline 60. Clock & $\mathbf{0}$ & 0 & 0 & 0 & 0 & 0 & Mantle clock \\
\hline 61. Clothespin & 0 & 0 & 2 & 0 & 0 & 0 & Clothes clip 3 , clip 2, clothes holder \\
\hline 62. Cloud & 0 & 1 & 0 & 7 & 0 & 0 & Bushes \\
\hline 63. Clown & 0 & 0 & 0 & 0 & 0 & 0 & Clown face 2 \\
\hline 64. Coat & 0 & 0 & 0 & 0 & 1 & 0 & Overcoat 6 , jacket 3 \\
\hline 65. Comb & 0 & 0 & 0 & 0 & 0 & 0 & Haircomb 2, pocket comb \\
\hline 66. Corn & 0 & 0 & 0 & 0 & 0 & 0 & Ear of corn 5, corn on a cob 3 \\
\hline 67. Couch & 0 & 0 & 0 & 0 & 0 & 0 & Sofa 14 \\
\hline 68. Cow & 0 & 0 & 0 & 0 & 0 & 0 & Bull 2, female cow \\
\hline 70. Cup & 0 & 0 & 0 & 0 & 0 & 0 & Coffee cup 2, teacup \\
\hline
\end{tabular}


Table C1 (continued)

\begin{tabular}{|c|c|c|c|c|c|c|c|}
\hline Concept & DKO & DKN & TOT & $\begin{array}{l}\text { DKO } \\
\text { (FAM) }\end{array}$ & NI & DO & Nondominant names \\
\hline 71. Deer & 0 & 0 & 0 & 0 & 0 & 0 & $\begin{array}{l}\text { Antelope } 3 \text {, reindeer } 2 \text {, elk 2, ram, } \\
\text { buck, stag }\end{array}$ \\
\hline 72. Desk & 0 & 0 & 0 & 0 & 0 & 1 & Bench, office desk \\
\hline 74. Doll & 0 & 0 & 0 & 1 & 0 & 0 & $\begin{array}{l}\text { Baby } 5 \text {, little girl } 4 \text {, female doll, } \\
\text { child, baby doll }\end{array}$ \\
\hline 75. Donkey & 0 & 0 & 0 & 0 & 0 & 0 & Mule 2, pony 2 , burro, jackass \\
\hline 76. Door & 0 & 0 & 0 & 0 & 0 & 0 & Wooden door \\
\hline 77. Doorknob & 0 & 0 & 1 & 0 & 0 & 0 & Knob 3 \\
\hline 79. Dresser & 0 & 0 & 0 & 0 & 0 & 0 & $\begin{array}{l}\text { Bureau } 7 \text {, chest of drawers } 6 \text {, chest } 6 \text {, } \\
\text { drawers } 4 \text {, dresser drawers } 2, \\
\text { bureau drawers, desk }\end{array}$ \\
\hline 80. Drum & 0 & 0 & 1 & 0 & 1 & 1 & - \\
\hline 81. Duck & $\mathbf{0}$ & 0 & 0 & 0 & 0 & 0 & Goose 2 \\
\hline 82. Eagle & 0 & 1 & 0 & 0 & 1 & 0 & Bird 4, hawk 3, bald eagle, parrot \\
\hline 83. Ear & 0 & 0 & 0 & 0 & 0 & 1 & Right ear 2 \\
\hline 85. Envelope & 0 & 0 & 0 & 0 & 0 & 0 & Sealed envelope \\
\hline 86. Eye & 0 & 0 & 0 & 0 & 0 & 0 & Eyeball \\
\hline 87. Fence & 0 & 0 & 0 & 0 & 0 & 1 & Picket fence 10 , gate \\
\hline 88. Finger & 0 & 0 & 0 & 0 & 0 & 0 & $\begin{array}{l}\text { Index finger } 7, \text { right index finger } 2, \\
\text { pointing finger, pointer, forefinger }\end{array}$ \\
\hline 90. Flag & 0 & 0 & 0 & $\mathbf{0}$ & 0 & 0 & Flag and staff, flag pole \\
\hline 91. Flower & 0 & 0 & 0 & 0 & 0 & 4 & Rose, marigold, daisy \\
\hline 92. Flute & 1 & 0 & 0 & 0 & 0 & 1 & Clarinet 2 , coronet, windpipe \\
\hline 93. Fly & 0 & 2 & 0 & 0 & 0 & 0 & Bug 3 , bce 2, insect, wasp, spider \\
\hline 94. Foot & 0 & 0 & 0 & 0 & 0 & 0 & Left foot 2 \\
\hline 96. Football helmet & 0 & 0 & 1 & 0 & 0 & 0 & Helmet 15 \\
\hline 98. Fox & 0 & 0 & 0 & 0 & 0 & 1 & Wolf $6, \operatorname{dog} 2$, coyote 2 , hound $\operatorname{dog}$ \\
\hline 99. French horn & 0 & 3 & 2 & 0 & 4 & 3 & $\begin{array}{l}\text { Tuba } 4 \text {, horn } 4 \text {, trumpet } 3 \text {, } \\
\text { trombone, coronet }\end{array}$ \\
\hline 101. Frying pan & 0 & 0 & 0 & 0 & 0 & 0 & Pan 15, fry pan 2 \\
\hline 102. Garbage can & 0 & 0 & 0 & 0 & 0 & 0 & $\begin{array}{l}\text { Trash can } 2 \text {, waste can, garbage } \\
\text { pail, garbage }\end{array}$ \\
\hline 103. Giraffe & 0 & 0 & 0 & 0 & 0 & 0 & Ostrich, zebra \\
\hline 104. Glass & 0 & 0 & 0 & 0 & 1 & 2 & Cup \\
\hline 105. Glasses & 0 & 0 & 0 & 0 & $n$ & 4 & Eve glasses 14 , wire-rim glasses \\
\hline 106. Glove & 0 & 0 & 0 & 0 & 0 & 0 & Right glove \\
\hline 107. Goat & 0 & 0 & 1 & 0 & 1 & 0 & Billy goat 2 , mule, horse, donkey \\
\hline 108. Gorilla & 0 & 0 & 0 & 0 & 0 & 0 & Ape 10 \\
\hline 109. Grapes & 0 & 0 & 1 & 0 & 0 & 0 & Bunch of grapes 3 \\
\hline 110. Grasshopper & 0 & 1 & 0 & 0 & 0 & 0 & $\begin{array}{l}\text { Bug } 4 \text {, cricket } 2 \text {, spider } 2 \text {, bee, } \\
\text { hornet, cicada }\end{array}$ \\
\hline 111. Guitar & 0 & 0 & 0 & 0 & 0 & 0 & Acoustic guitar \\
\hline 112. Gun & 0 & 0 & 0 & 0 & 0 & 0 & Pistol 6, revolver 5 \\
\hline 113. Hair & 0 & 0 & 0 & 1 & 1 & 6 & $\begin{array}{l}\text { Straight hair, women's hair style, } \\
\text { hair style, head of hair }\end{array}$ \\
\hline 115. Hand & 0 & 0 & 0 & 0 & 0 & 0 & Right hand 2 , fingers \\
\hline 116. Hanger & 0 & 0 & 0 & 0 & 0 & 3 & Clothes hanger 3 , coat hanger 3 \\
\hline 117. Harp & 0 & 0 & 3 & 0 & 1 & 0 & - \\
\hline 118. Hat & 0 & 0 & 0 & 0 & 0 & 0 & Felt hat \\
\hline 119. Heart & 0 & 0 & 0 & 0 & 0 & 3 & - \\
\hline 120. Helicopter & 0 & 0 & 0 & 0 & 0 & 0 & Plane, copter \\
\hline 122. House & 0 & 0 & 0 & 0 & 0 & 0 & Cottage, private house \\
\hline
\end{tabular}

(table continued) 


\begin{tabular}{|c|c|c|c|c|c|c|c|}
\hline Concept & DKO & $\mathrm{DKN}$ & TOT & $\begin{array}{l}\mathrm{DKO} \\
(\mathrm{FAM})\end{array}$ & NI & DO & Nondominant names \\
\hline 123. Iron & 0 & 0 & 0 & 0 & 1 & 0 & Cloth iron, steam iron \\
\hline 124. Ironing board & 0 & 1 & 2 & 0 & 0 & 0 & Iron board 3 , ironing table \\
\hline 125. Jacket & 0 & 0 & 0 & 0 & 0 & 0 & Shirt 5 , coat 2 , sport jacket \\
\hline 127. Kettle & 0 & 0 & 0 & 0 & 0 & 1 & Tea kettle 15 , teapot 9 , pot \\
\hline 130. Knife & 0 & 0 & 0 & 0 & 0 & 0 & $\begin{array}{l}\text { Eating knife } 2 \text {, butter knife, table } \\
\text { knife }\end{array}$ \\
\hline 131. Ladder & 0 & 0 & 0 & 0 & 0 & 0 & Part of a ladder \\
\hline 132. Lamp & 0 & 0 & 0 & 0 & 0 & 0 & Table lamp 2, lamp \& shade \\
\hline 133. Leaf & 0 & 0 & 0 & 0 & 0 & 0 & Maple leaf 3 , oak leaf \\
\hline 134. Leg & 0 & 0 & 0 & 0 & 0 & 1 & $\begin{array}{l}\text { Knee } 3 \text {, right leg } 2 \text {, knee to foot, } \\
\text { foot, calf }\end{array}$ \\
\hline 136. Leopard & 0 & 0 & 2 & 0 & 0 & 0 & Tiger 4 , panther 2 , jaguar, checqwa \\
\hline 137. Lettuce & 2 & 0 & 0 & 0 & 0 & 0 & $\begin{array}{l}\text { Cabbage 5, cauliflower } 2 \text {, celery, } \\
\text { head of lettuce }\end{array}$ \\
\hline 138. Light bulb & 0 & 0 & 0 & 0 & 0 & 0 & Bulb 5, incandescent light bulb \\
\hline 139. Light switch & 0 & 0 & 0 & 0 & 0 & 0 & Switch 14 \\
\hline 140. Lion & 0 & 0 & 0 & 0 & 0 & 0 & Male lion 3 \\
\hline 141. Lips & 0 & 0 & 0 & 0 & 0 & 0 & Mouth 2, pair of lips \\
\hline 142. Lobster & 0 & 1 & 0 & 0 & 0 & 0 & Crab 3 \\
\hline 143. Lock & 0 & 0 & $\mathbf{0}$ & 0 & 0 & 5 & Padlock 5 \\
\hline 144. Mitten & 0 & 0 & 0 & 0 & 1 & 0 & Glove 8 , left mitten 2 \\
\hline 145. Monkey & 0 & 0 & 0 & 0 & 0 & 0 & Chimp, chimpanzee \\
\hline 146. Moon & 0 & 0 & 0 & 0 & 0 & 1 & $\begin{array}{l}\text { Quarter moon } 6 \text {, crescent moon } 4 \text {, } \\
\text { half moon } 4 \text {, crescent } 2\end{array}$ \\
\hline 147. Motorcycie & 0 & 0 & 0 & 0 & 1 & 0 & Motor bike, bike \\
\hline 148. Mountain & 0 & 0 & 0 & 0 & 0 & 0 & Mountain peak 2, snowcap, hill \\
\hline 149. Mouse & 0 & 0 & 0 & 0 & 0 & 0 & Rat 9 \\
\hline 150. Mushroom & 0 & 0 & 1 & 0 & 0 & 0 & - \\
\hline 151. Nail & 0 & 0 & 0 & 0 & 0 & 7 & Spike \\
\hline 152. Nail file & 0 & 0 & 0 & 0 & 1 & 0 & File 13, fingernail file \\
\hline 153. Necklace & 0 & 0 & 0 & 0 & 0 & 0 & $\begin{array}{l}\text { Pearl necklace } 5 \text {, beads } 5 \text {, pearls } 4 \text {, } \\
\text { chain, pearl chain, string of pearls }\end{array}$ \\
\hline 154. Needle & 0 & 0 & 0 & 0 & 0 & 2 & Pin 6, sewing needle 2 \\
\hline 155. Nose & 0 & 0 & 0 & 0 & 0 & 0 & Left nostril \\
\hline 156. Nut & 0 & 3 & 2 & 0 & 1 & 31 & Bolt 9, hexagonal nut \\
\hline 157. Onion & 1 & 0 & 1 & 0 & 0 & 0 & - \\
\hline 158. Orange & 4 & 0 & 1 & 2 & 0 & 0 & Ball, grapefruit, fruit \\
\hline 159. Ostrich & 0 & 2 & 2 & 0 & 2 & 0 & Stork, turkey \\
\hline 161. Paintbrush & 0 & 0 & 0 & 0 & 0 & 1 & Brush 9 , ink pen, mk pen \\
\hline 162. Pants & 0 & 0 & 0 & 0 & 0 & 0 & Slacks 5 \\
\hline 163. Peach & 2 & 0 & 1 & 2 & 0 & 0 & Apple 2, pear 2, plum 2, fruit, orange \\
\hline 164. Peacock & 0 & 0 & 4 & 0 & 1 & 0 & Turkey 2 , rooster, ostrich, bird \\
\hline 165. Peanut & 0 & 0 & 0 & 0 & 0 & 0 & Nut 3 \\
\hline 167. Pen & 0 & 0 & 0 & $\mathbf{0}$ & 0 & 0 & Writing pen, ball point pen \\
\hline 169. Penguin & 0 & 1 & 0 & 0 & 0 & 0 & Pelican 3 \\
\hline 170. Pepper & 1 & 2 & 1 & 1 & 0 & 7 & $\begin{array}{l}\text { Green pepper } 8 \text {, artichoke, bell } \\
\text { pepper }\end{array}$ \\
\hline 171. Piano & 0 & 0 & 0 & 0 & 0 & 0 & Grand piano 8 \\
\hline 172. Pig & 0 & 0 & 0 & 0 & 0 & 0 & Hog 2, rhinoceros, bull \\
\hline 174. Pipe & 0 & 0 & 0 & 0 & 0 & 5 & Pipe (tobacco) \\
\hline
\end{tabular}

(table continued) 
Table C1 (continued)

\begin{tabular}{|c|c|c|c|c|c|c|c|}
\hline Concept & DKO & DKN & TOT & $\begin{array}{c}\text { DKO } \\
\text { (FAM) }\end{array}$ & $\mathrm{NI}$ & DO & Nondominant names \\
\hline 175. Pitcher & 0 & 1 & 0 & 0 & 0 & 6 & Jug 3 , water pitcher \\
\hline 176. Pliers & $\mathbf{0}$ & 1 & 1 & 0 & 0 & 0 & Wrench 3 \\
\hline 177. Plug & 0 & 1 & 2 & 0 & 0 & 3 & Electric plug 2 \\
\hline 178. Pocketbook & $\mathbf{0}$ & 0 & 0 & 0 & 0 & 0 & $\begin{array}{l}\text { Handbag } 7 \text {, purse } 7 \text {, bag } 3 \text {, } \\
\text { shoulder bag }\end{array}$ \\
\hline 179. Pot & 0 & 0 & 0 & 0 & 0 & 4 & Pan 6, saucepan 2 \\
\hline 180. Potato & 2 & 0 & 0 & 1 & 1 & 0 & Peanut, acorn \\
\hline 181. Pumpkin & 0 & 0 & 1 & 0 & 0 & 0 & - \\
\hline 183. Raccoon & 1 & 1 & 3 & 0 & 2 & 0 & Fox 3, badger \\
\hline 184. Record player & 0 & 0 & 1 & 0 & 0 & 0 & $\begin{array}{l}\text { Phonograph } 12 \text {, turntable } 5 \text {, } \\
\text { stereo } 2 \text {, phono }\end{array}$ \\
\hline 185. Refrigerator & 0 & 0 & 0 & 0 & 0 & 0 & Ice box 2 , refrigidaire \\
\hline 186. Rhinoceros & 0 & 1 & 2 & 0 & 2 & 0 & Rhino 3, hippopotamus \\
\hline 187. Ring & 0 & 0 & 0 & 0 & 0 & 0 & Pearl ring \\
\hline 188. Rocking chair & 0 & 0 & 0 & 0 & 0 & 0 & Chair 3 , rocker \\
\hline 189. Roller skate & 0 & 0 & 0 & 0 & 0 & 0 & Skate 20 \\
\hline 190. Rolling pin & 0 & 3 & 1 & 0 & 1 & 3 & Roller 5 , dough roller 3 \\
\hline 191. Rooster & 0 & 0 & 0 & 0 & 0 & 0 & Chicken 5 , hen 2 , turkey 2 , cock \\
\hline 192. Ruler & 0 & 0 & 0 & 0 & 0 & 0 & 12 -inch ruler \\
\hline 193. Sailboat & 0 & 0 & 0 & 0 & 0 & 0 & Boat 3 \\
\hline 194. Salt shaker & 0 & 0 & 0 & 0 & 0 & 0 & $\begin{array}{l}\text { Salt or pepper shaker } 3 \text {, shaker } 2 \text {, } \\
\text { salt container, pepper shaker }\end{array}$ \\
\hline 196. Saw & 0 & 0 & 0 & 0 & 0 & 0 & Hand saw \\
\hline 197. Scissors & 0 & 0 & $\mathbf{0}$ & 0 & 0 & 0 & Sewing scissors \\
\hline 198. Screw & 0 & 0 & 1 & 0 & 0 & 1 & Screw-round head wood \\
\hline 199. Screwdriver & 0 & 0 & 1 & 0 & 0 & 0 & - \\
\hline 200. Sea horse & 0 & 3 & 0 & 0 & 0 & 0 & Fish, dragon \\
\hline 201. Seal & 0 & 0 & 1 & 0 & 0 & 1 & Walrus 2, otter, sea lion \\
\hline 202. Sheep & 0 & 3 & 1 & 0 & 1 & 0 & Lamb 9 , bull \\
\hline 204. Shoe & 0 & 0 & 0 & 0 & 0 & 0 & Right shoe 2 \\
\hline 205. Skirt & 0 & 0 & 0 & 1 & 0 & 0 & Dress \\
\hline 206. Skunk & 0 & 0 & 0 & 0 & 2 & 0 & Raccoon \\
\hline 207. Sled & 0 & 0 & 1 & 0 & 1 & 0 & - \\
\hline 208. Snail & 1 & 1 & 1 & 0 & 1 & 0 & Slug, shell, snail shell \\
\hline 209. Snake & 0 & 0 & 0 & 0 & 0 & 1 & Cobra \\
\hline 212. Spider & 0 & 1 & 0 & 0 & 0 & 0 & Insect 2 , praying mantis, bug \\
\hline 213. Spinning wheel & 0 & 5 & 3 & 0 & 5 & 5 & $\begin{array}{l}\text { Loom } 3 \text {, sewing machine } 3 \text {, spindle } \\
2 \text {, wheel to make clothes, } \\
\text { knitting wheel, knitting } \\
\text { mill, wool, spinwheel }\end{array}$ \\
\hline 214. Spool of thread & 0 & 0 & 0 & 0 & 0 & 0 & $\begin{array}{l}\text { Thread 11, spool 7, spool of sew } \\
\text { thread }\end{array}$ \\
\hline 215. Spoon & 0 & 0 & 0 & 0 & 0 & 0 & Teaspoon \\
\hline 216. Squirrel & 0 & 0 & 2 & 0 & 0 & 0 & Chipmunk \\
\hline 217. Star & 0 & 0 & 0 & 0 & 0 & 1 & - \\
\hline 218. Stool & 0 & 0 & 0 & 0 & 0 & 0 & Chair \\
\hline 219. Stove & 0 & 0 & 0 & 0 & 0 & 0 & Oven 5 , range 4 , gas stove \\
\hline 220. Strawberry & 1 & 1 & 1 & 0 & 0 & 0 & Raspberry \\
\hline 221. Suitcase & 0 & 0 & $i$ & 0 & 0 & 0 & $\begin{array}{l}\text { Luggage } 5 \text {, valise, piece of luggage, } \\
\text { canvas luggage }\end{array}$ \\
\hline 223. Swan & 0 & 0 & 0 & 0 & 1 & 0 & Goose 3, duck 2 \\
\hline 224. Sweater & 0 & 0 & 0 & 0 & 0 & 0 & $\begin{array}{l}\text { Pullover } 2 \text {, shirt } 2 \text {, sweat shirt } 2 \text {, } \\
\text { pull over sweater }\end{array}$ \\
\hline 225. Swing & 0 & 1 & 0 & 0 & 1 & 0 & Swinging chair \\
\hline
\end{tabular}


Table C1 (continued)

\begin{tabular}{|c|c|c|c|c|c|c|c|}
\hline Concept & DKO & DKN & TOT & $\begin{array}{c}\mathrm{DKO} \\
(\mathrm{FAM})\end{array}$ & $\mathrm{NI}$ & DO & Nondominant names \\
\hline 226. Table & 0 & 0 & 0 & 0 & 0 & 0 & Desk, bench \\
\hline 227. Telephone & 0 & 0 & 0 & 0 & 0 & 0 & Phone 6 \\
\hline 228. Television & 0 & 0 & 0 & 0 & 0 & 1 & TV 12 , television set 8 \\
\hline 229. Tennis racket & 0 & 0 & 1 & 0 & 0 & 0 & Racket 4, paddle \\
\hline 230. Thimble & 0 & 0 & 3 & 0 & 0 & 1 & $\begin{array}{l}\text { Nimble } 2 \text {, thumb nimble, thumb } \\
\text { cap }\end{array}$ \\
\hline 231. Thumb & 0 & 0 & 0 & 0 & 0 & 0 & Finger \\
\hline 232. Tie & 0 & 0 & 0 & 0 & 0 & 2 & Necktie 13 \\
\hline 233. Tiger & 0 & 0 & 1 & 0 & 0 & 0 & Leopard, lion \\
\hline 235. Toe & 0 & 0 & 0 & 0 & 0 & 0 & Big toe 12 , toes 5 , right big toe 2 \\
\hline 236. Tomato & 0 & 0 & 0 & 0 & 0 & 0 & Pepper, radish, onion, peach, fruit \\
\hline 237. Toothbrush & 0 & 0 & 0 & 0 & 0 & 0 & Brush \\
\hline 238. Top & 0 & 0 & 0 & 0 & 2 & 5 & Spinning top 5, draddle \\
\hline 239. Traffic light & 0 & 0 & 0 & 0 & 0 & 0 & $\begin{array}{l}\text { Stop light } 10 \text {, street light, signal } \\
\text { light, crossing lights, light }\end{array}$ \\
\hline 240. Train & 0 & 0 & 0 & 0 & 0 & 0 & Locomotive 3 , train engine 3 \\
\hline 242. Truck & 0 & 0 & 0 & 0 & 0 & 0 & Tractor trailer 3 , trailer \\
\hline 243. Trumpet & 0 & 0 & 0 & 0 & 0 & 0 & Horn 5 , bugle 2 , tuba, coronet \\
\hline 244. Turtle & 0 & 0 & 0 & 0 & 0 & 0 & Tortoise, box turtle \\
\hline 246. Vase & 0 & 0 & 0 & 0 & 0 & 0 & Flowered vase \\
\hline 247. Vest & 0 & 0 & 0 & 0 & 0 & 0 & Vestcoat \\
\hline 248. Violin & 0 & 0 & 0 & 0 & 0 & 0 & Base 4 , cello 2 \\
\hline 249. Wagon & 0 & 1 & 1 & $\mathbf{0}$ & 0 & 6 & Cart 3 , wheelbarrow 3 , carriage \\
\hline 250. Watch & 0 & 0 & 0 & 0 & 0 & 0 & Wrist watch 4 \\
\hline 251. Watering can & 0 & 1 & 4 & 0 & 2 & 0 & $\begin{array}{l}\text { Sprinkler } 5 \text {, watering pot } 2 \text {, pitcher, } \\
\text { water planter, flower waterer, } \\
\text { water pitcher, water can, water } \\
\text { basket, pot }\end{array}$ \\
\hline 252. Watermelon & 2 & 0 & 0 & 0 & 0 & 1 & Watermelon slice 3 , melon \\
\hline 253. Well & 0 & 0 & 0 & 0 & 0 & 0 & $\begin{array}{l}\text { Water well } 2 \text {, waterbucket, } \\
\text { wishing well }\end{array}$ \\
\hline 254. Wheel & 0 & 0 & 1 & 0 & 0 & 0 & Wagon wheel, spoked wheel \\
\hline 256. Windmill & 0 & 0 & 0 & $\mathbf{0}$ & 0 & 0 & Windbraker \\
\hline 257. Window & 0 & $\mathbf{0}$ & 0 & 0 & 0 & 0 & Window-double hung, closed window \\
\hline 258. Wineglass & 0 & 0 & 0 & 0 & 0 & 0 & Glass 15 , goblet 6 \\
\hline 259. Wrench & 0 & 5 & 0 & 0 & 2 & 3 & $\begin{array}{l}\text { Pliers, belt turner, spanouke, } \\
\text { open end wrench, crescent wrench }\end{array}$ \\
\hline 260. Zebra & 0 & 1 & 0 & 0 & 0 & 0 & 一 \\
\hline
\end{tabular}

Received June 18, 1979 Revision received August 24, 1979 